LA-14258

Approved for public release;

distribution is unlimited.

\title{
A Calibration to Predict the Concentrations of Impurities in Plutonium Oxide by \\ Prompt Gamma Analysis
}


This work was supported by the U.S. Department of Energy, Office of Environmental Management.

Los Alamos National Laboratory, an affirmative action/ equal opportunity employer, is operated by the University of California for the United States Department of Energy under contract W-7405-ENG-36.

This report was prepared as an account of work sponsored by an agency of the United States Government. Neither the Regents of the University of California, the United States Government nor any agency thereof, nor any of their employees make any warranty, express or implied, or assume any legal liability or responsibility for the accuracy, completeness, or usefulness of any information, apparatus, product, or process disclosed, or represent that its use would not infringe privately owned rights. Reference herein to any specific commercial product, process, or service by trade name, trademark, manufacturer, or otherwise does not necessarily constitute or imply its endorse-ment, recommendation, or favoring by the Regents of the University of California, the United States Government, or any agency thereof. The views and opinions of authors expressed herein do not necessarily state or reflect those of the Regents of the University of California, the United States Government, or any agency thereof. Los Alamos National Laboratory strongly supports academic freedom and a researcher's right to publish; as an institution, however, the Laboratory does not endorse the viewpoint of a publication or guarantee its technical correctness. 
LA-14258

Issued: December 2005

A Calibration to Predict the Concentrations of

Impurities in Plutonium Oxide by

Prompt Gamma Analysis

\author{
Joshua E. Narlesky \\ Elizabeth J. Kelly \\ Lynn A. Foster
}





\section{TABLE OF CONTENTS}

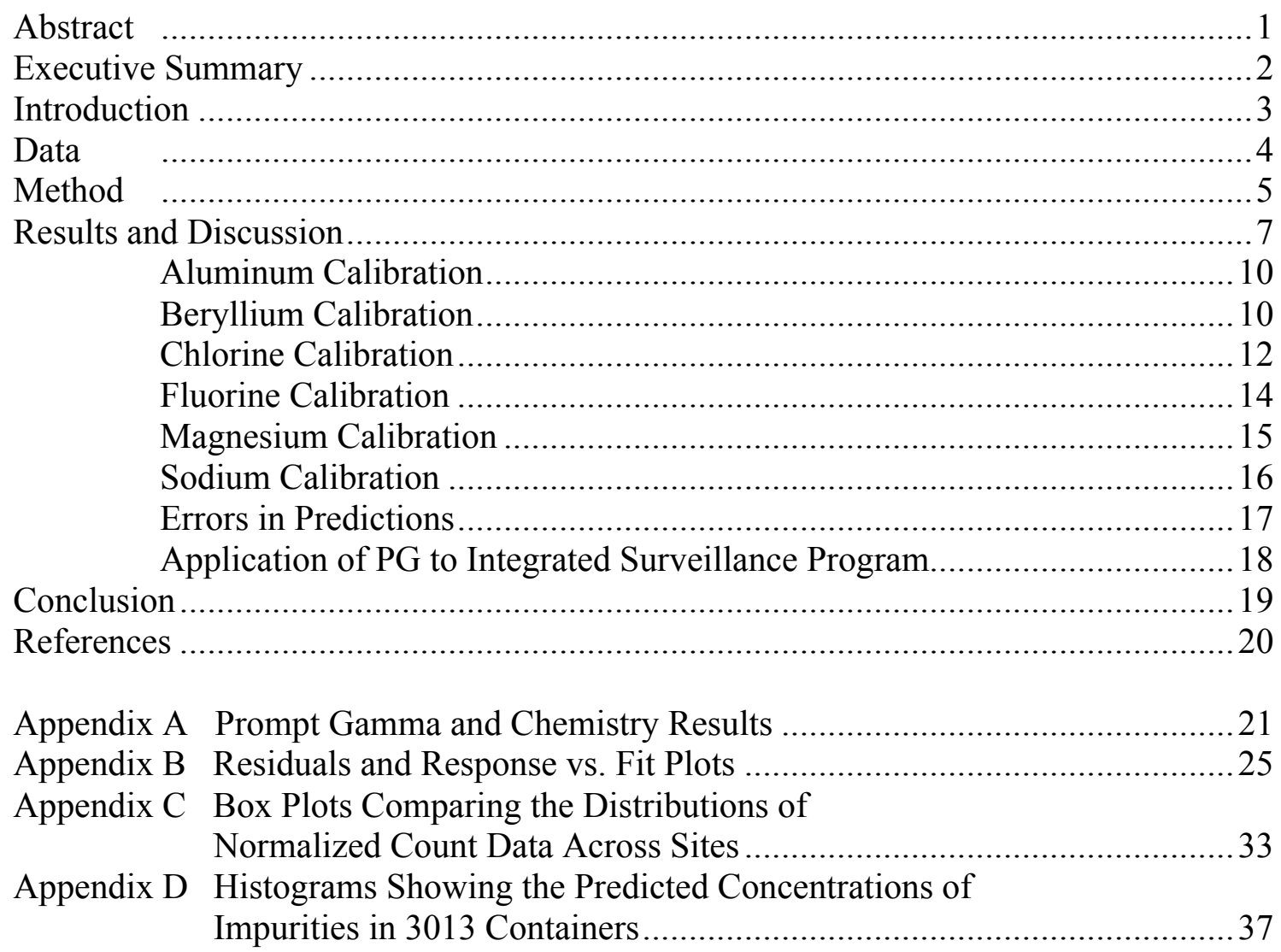

\section{LIST OF FIGURES}

Figure 1. (a) Raw data of $\mathrm{Cl}$ concentration in ppm as a function of normalized count rate (left), (b) same data using log-log transform (right).................... 7

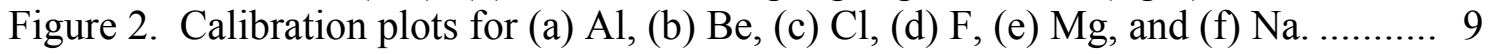

Figure 3. Comparison of $\mathrm{Al}$ predictions with measured data....................................... 10

Figure 4. Comparison of Be predictions with measured data....................................... 11

Figure 5. Comparison of $\mathrm{Cl}$ predictions with measured data..................................... 13

Figure 6. Comparison of $\mathrm{F}$ predictions with measured data......................................... 15

Figure 7. Comparison of $\mathrm{Mg}$ predictions with measured data. ..................................... 16

Figure 8. Comparison of $\mathrm{Na}$ predictions with measured data. ..................................... 17

Figure B-1. Actual data vs. fit data for the Al calibration.......................................26

Figure B-2. Residuals plot showing the differences between the actual and predicted values for the $\mathrm{Al}$ calibration line...........................................26

Figure B-3. Actual data vs. fit data for the Be calibration. .......................................2 
Figure B-4. Residuals plot showing the differences between the actual and predicted values for the Be calibration line.

Figure B-5. Actual data vs. fit data for the $\mathrm{Cl}$ calibration.....................................2. 28

Figure B-6. Residuals plot showing the differences between the actual and predicted values for the $\mathrm{Cl}$ calibration line.......................................28

Figure B-7. Actual data vs. fit data for the F calibration................................... 29

Figure B-8. Residuals plot showing the differences between the actual and predicted values for the $\mathrm{F}$ calibration line. .........................................2. 29

Figure B-9. Actual data vs. fit data for the Mg calibration. ................................... 30

Figure B-10. Residuals plot showing the differences between the actual and predicted values for the $\mathrm{Mg}$ calibration line. .................................... 30

Figure B-11. Actual data vs. fit data for the Na calibration. ................................. 31

Figure B-12. Residuals plot showing the differences between the actual and predicted values for the $\mathrm{Na}$ calibration line. ..................................... 31

Figure C-1. Box plots comparing the ranges of count data for Al across all sites. ..... 34

Figure C-2. Box plots comparing the ranges of count data for Be across all sites......34

Figure $\mathrm{C}-3$. Box plots comparing the ranges of count data for $\mathrm{Cl}$ across all sites....... 35

Figure $\mathrm{C}-4$. Box plots comparing the ranges of count data for $\mathrm{F}$ across all sites. ....... 35

Figure $\mathrm{C}-5$. Box plots comparing the ranges of count data for $\mathrm{Mg}$ across all sites..... 36

Figure C-6. Box plots comparing the ranges of count data for $\mathrm{Na}$ across all sites......36

Figure D-1. Distribution of aluminum in 3013 containers. ...................................... 38

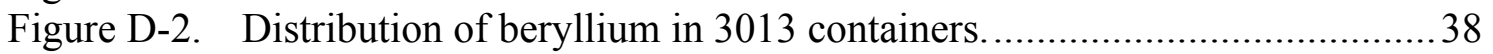

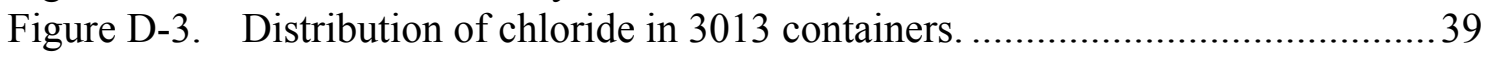

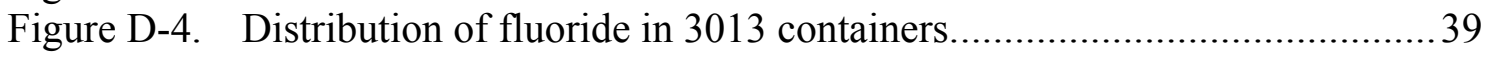

Figure D-5. Distribution of magnesium in 3013 containers. ................................. 40

Figure D-6. Distribution of sodium in 3013 containers. ..................................... 40

\section{LIST OF TABLES}

Table 1. Primary and secondary peak for identification ................................... 4

Table 2. Primary peak energies and detection limits for PG sensitive elements......... 6

Table 3. Calibration parameters ....................................................................... 8

Table 4. Comparison of Hanford and LANL calibrations.......................................... 14

Table 5. PG Results from a PuO2-Salt mixture prepared and calcined at various temperatures ............................................................................. 18

Table 6. Concentration ranges based on predicted concentration distributions ............ 19

Table A-1. Prompt gamma normalized count data for the respective $\mathrm{Al}, \mathrm{Be}, \mathrm{Cl}, \mathrm{F}$, $\mathrm{Mg}, \mathrm{K}$, and $\mathrm{Na}$ peaks for the MIS items ........................................22

Table A-2. Chemistry data for MIS items included in regression analysis.................23 


\title{
A Calibration to Predict the Concentrations of Impurities in Plutonium Oxide by Prompt Gamma Analysis
}

\author{
by \\ Joshua E. Narlesky, Elizabeth J. Kelly, and Lynn A. Foster
}

\begin{abstract}
Prompt gamma (PG) analysis has been used to identify the presence of certain impurities in plutonium oxide, which has been stored in 3013 containers. A regression analysis was used to evaluate the trends between the count rates obtained from PG analysis and the concentration of the impurities in plutonium oxide samples measured by analytical chemistry techniques. The results of the analysis were used to obtain calibration curves, which may be used to predict the concentration of $\mathrm{Al}, \mathrm{Be}, \mathrm{Cl}, \mathrm{F}, \mathrm{Mg}$, and $\mathrm{Na}$ in the 3013 containers. The scatter observed in the data resulted from several factors including sample geometry, error in sampling for chemical assay, statistical counting error, and intimacy of mixing of impurities and plutonium. Standards prepared by mixing plutonium oxide with $\mathrm{CaF}_{2}, \mathrm{NaCl}$, and $\mathrm{KCl}$ show that intimacy mixing and sampling error have the largest influence on the results. Although these factors are difficult to control, the calibrations are expected to yield semiquantitative results that are sufficient for the purpose of ordering or ranking.
\end{abstract}




\section{Executive Summary}

Prompt gamma (PG) analysis has been used to identify the presence of impurities in plutonium oxide stored in over twenty-nine hundred 3013 containers as part of the 94-1 Integrated Surveillance and Monitoring Program (ISP) [1]. Certain impurities, particularly $\mathrm{Cl}, \mathrm{F}$, and $\mathrm{Mg}$ are of concern for long-term storage, as they may increase the risk of container degradation over time [2]. As part of the ISP, annual surveillance sampling to evaluate container integrity is done and consists of a random statistical sample and a focused or engineering judgment sample. The judgmental sampling evaluates those containers with the greatest risk of degradation based on current knowledge. To improve confidence in judgmental sampling, a method for determining the relative concentrations of impurities in the containers is needed. This paper describes the approach used to develop semiquantitative estimates of container impurity concentrations based on PG data.

The approach uses data from the Materials Identification and Surveillance (MIS) containers to construct calibration curves. There are 68 MIS items: 19 from Hanford, 27 from Rocky Flats Environmental Site (RFETS), and 22 from Los Alamos National Laboratory (LANL). Many of the MIS items have been studied extensively at LANL. Analyses include determining physical properties, such as particle size, density, and surface area, as well as moisture evaluations [3]. Approximately 25 of the MIS containers have data for both PG and chemical concentrations. However, not all of the 25 items have data for all of the chemicals of interest. The calibration curves based on these data allow the ordering and relative ranking of the concentrations of $\mathrm{Al}, \mathrm{Be}, \mathrm{Cl}, \mathrm{F}$, $\mathrm{Mg}$, and $\mathrm{Na}$ in ppm in 3013 containers with plutonium oxide based on the normalized count rates of the characteristic PG rays.

Previous work indicated a trend between count rate and concentration [4]. However, the data were quite variable due to inhomogeneous chemistry samples and errors in the PG count. This study includes more chemistry and PG data from the MIS inventory. The same variability is seen in these data, but a log-log transform of both the chemistry and normalized count rate is used in the analysis to reduce the scatter in the data and stabilize the variance. The transformed data show a strong linear trend and the results are supported by prompt gamma and chemistry measurements done at other sites.

The MIS data do not cover the entire range of the 3013 container PG data. For those containers outside the MIS data range, estimates must be extrapolated. The appropriateness of extrapolation is also discussed in the report. 


\section{Introduction}

Prompt gamma (PG) analysis is a nondestructive nuclear technique, which has been used as part of the Integrated Surveillance Program (ISP) to determine the impurities present in plutonium oxide materials for the past five years. As shown by previous research, PG analysis can be used to detect certain impurities in ${ }^{238} \mathrm{PuO}_{2}$ and ${ }^{239} \mathrm{PuO}_{2}$ through the characteristic gamma rays emitted from $(\alpha, n \gamma)$ and $(\alpha, p \gamma)$ reactions $[5,6]$. Of the impurities commonly found in plutonium oxide, the impurities detectable by PG analysis include $\mathrm{Al}, \mathrm{Be}, \mathrm{Cl}, \mathrm{F}, \mathrm{Mg}, \mathrm{P}, \mathrm{K}$, and $\mathrm{Na}$; $\mathrm{PG}$ rays from the following reactions are observed.

$$
\begin{gathered}
{ }_{13}^{27} \mathrm{Al}+{ }_{2}^{4} \alpha \longrightarrow{ }_{14}^{30} \mathrm{Si}^{*}+\mathrm{p} ; \quad{ }_{14}^{30} \mathrm{Si}^{*} \longrightarrow{ }_{14}^{30} \mathrm{Si}+\gamma(2236 \mathrm{keV}) \\
{ }_{4}^{9} \mathrm{Be}+{ }_{2}^{4} \alpha \longrightarrow{ }_{6}^{12} \mathrm{C}^{*}+\mathrm{n} ;{ }_{6}^{12} \mathrm{C}^{*} \longrightarrow{ }_{6}^{12} \mathrm{C}+\gamma(4439 \mathrm{keV}) \\
{ }_{17}^{35} \mathrm{Cl}+{ }_{2}^{4} \alpha \longrightarrow{ }_{18}^{38} \mathrm{Ar}^{*}+\mathrm{p} ;{ }_{18}^{38} \mathrm{Ar}^{*} \longrightarrow{ }_{18}^{38} \mathrm{Ar}+\gamma(2167 \mathrm{keV}) \\
{ }_{9}^{19} \mathrm{~F}+{ }_{2}^{4} \alpha \longrightarrow{ }_{11}^{22} \mathrm{Na}^{*}+\mathrm{n} ;{ }_{11}^{22} \mathrm{Na}^{*} \longrightarrow{ }_{11}^{22} \mathrm{Na}+\gamma(891 \mathrm{keV}) \\
{ }_{12}^{25} \mathrm{Mg}+{ }_{2}^{4} \alpha \longrightarrow{ }_{14}^{28} \mathrm{Si}^{*}+\mathrm{n} ;{ }_{14}^{28} \mathrm{Si}^{*} \longrightarrow{ }_{14}^{28} \mathrm{Si}+\gamma(1779 \mathrm{keV}) \\
{ }_{15}^{31} \mathrm{P}+{ }_{2}^{4} \alpha \longrightarrow{ }_{16}^{34} \mathrm{~S}^{*}+\mathrm{p} ;{ }_{16}^{34} \mathrm{~S}^{*} \longrightarrow{ }_{16}^{34} \mathrm{~S}+\gamma(2127 \mathrm{keV}) \\
{ }_{19}^{39} \mathrm{~K}+{ }_{2}^{4} \alpha \longrightarrow{ }_{20}^{42} \mathrm{Ca}^{*}+\mathrm{p} ;{ }_{20}^{42} \mathrm{Ca}^{*} \longrightarrow{ }_{20}^{42} \mathrm{Ca}+\gamma(1524 \mathrm{keV}) \\
{ }_{11}^{23} \mathrm{Na}+{ }_{2}^{4} \alpha \longrightarrow{ }_{13}^{26} \mathrm{Mg}^{*}+\mathrm{p} ;{ }_{13}^{26} \mathrm{Mg}^{*} \longrightarrow{ }_{13}^{26} \mathrm{Mg}+\gamma(1808 \mathrm{keV})
\end{gathered}
$$

Since chemical analysis is not available on most 3013 containers, PG analysis has been used to determine the presence of impurities in 2,959 plutonium oxide and metal containers from Hanford, Lawrence Livermore National Laboratory (LLNL), Rocky Flats Environmental Site (RFETS), and Savannah River Site (SRS). These materials have undergone stabilization for packaging in a 3013 container and storage as part of the 94-1 program. The analytical emphasis has been to identify 3013 containers at risk for pressurization and/or corrosion due to the presence of fluoride or chloride salts and to determine "Representation" in the Materials Identification and Surveillance (MIS) Program. Representation is evaluated by matching the PG spectrum of a 3013 container to the PG spectrum of a fully-characterized MIS item.

The information provided by PG analysis is available in the ISP database. The qualitative PG data have been used to guide judgmental sampling for surveillance activities. However, a quantitative method to order or rank concentrations for the corrosive elements will improve judgmental sampling by helping to identify those items with the highest level of impurities.

Using the PG spectra and characterization data available for the MIS items, we have constructed calibration curves to predict the concentration of the corrosive elements, $\mathrm{Cl}$ and $\mathrm{F}$ based on the intensity of the $\mathrm{PG}$ signal. In addition, we have included the results 
for the noncorrosive elements, $\mathrm{Al}, \mathrm{Be}, \mathrm{Mg}$, and $\mathrm{Na}$, to provide additional information for surveillance sampling.

\section{Data}

At the various sites, PG spectra have been measured on material that has been stabilized at $950{ }^{\circ} \mathrm{C}$ for 2 hours and sealed in stainless steel 3013 containers. Likewise, PG measurements for the MIS items were also taken after stabilization at $950{ }^{\circ} \mathrm{C}$. It has been shown that heating the material at $800{ }^{\circ} \mathrm{C}$ may increase the $\mathrm{PG}$ signal with respect to asreceived material if intimate mixing has not already occurred [4]. This effect is marginal for temperatures higher than $800{ }^{\circ} \mathrm{C}$, since the melting points of primary impurities $\mathrm{NaCl}$ and $\mathrm{KCl}$ are $801{ }^{\circ} \mathrm{C}$ and $770{ }^{\circ} \mathrm{C}$, respectively. Therefore, we expect that intimate mixing of the impurities and the plutonium has occurred in the containers and that the PG results are quantitative.

All gamma-ray spectra were measured using high-purity germanium detectors and analyzed with the Prompt Gamma Analysis Software V 4.4 developed at Los Alamos National Laboratory (LANL). The software reads the raw spectrum file produced by the Ortec ${ }^{\circledR}$ data collection system, computes an energy calibration, locates all peaks in the spectrum, and computes the area under each peak. The peaks are then matched with their corresponding isotopes using a peak identification routine. The identification routine resolves interferences using the combination of primary and secondary peaks and reports the elements present along with the intensity of the peak. The peaks used to resolve interferences and positively identify each element are shown in Table 1.

Table 1. Primary and secondary peak for identification

\begin{tabular}{|c|c|}
\hline \multirow{2}{*}{ Element } & $\begin{array}{c}\text { Primary / Secondary } \\
\text { Energy } \\
\text { (keV) }\end{array}$ \\
\hline $\mathrm{Be}$ & 4439 \\
\hline $\mathrm{F}$ & $1274 / 891$ \\
\hline $\mathrm{Na}$ & 1808 \\
\hline $\mathrm{Mg}$ & $1273 / 1779$ \\
\hline $\mathrm{Al}$ & 2236 \\
\hline $\mathrm{P}$ & 2127 \\
\hline $\mathrm{Cl}$ & 2167 \\
\hline $\mathrm{K}$ & 1524 \\
\hline
\end{tabular}

However, some of the measurement conditions such as container thickness, count time, distance to the detector, and presence of low-energy absorbers vary from site to site. In addition, the isotopic content varies from container to container, but it is assumed that the primary alpha particle production is due to ${ }^{239} \mathrm{Pu}$ and ${ }^{241} \mathrm{Am}$. Therefore, we used an internal standardization method to normalize the data and apply corrections for count time, geometry, and detector efficiency. The normalization constant $\mathrm{N}$ (1) was obtained from count rates and branching ratios of the ${ }^{239} \mathrm{Pu}$ and ${ }^{241} \mathrm{Am}$ peaks at $414-\mathrm{keV}$ and $662-\mathrm{keV}$. 


$$
N=\left(\frac{A_{414 \mathrm{keV}}}{B_{414 \mathrm{keV}}}+\frac{A_{662 \mathrm{keV}}}{B_{662 \mathrm{keV}}}\right) / 10^{6}
$$

The variable A represents net area under the respective 414- and 662-keV peaks, and B is the branching ratio, which gives the number of gamma rays emitted per alpha particle. The normalized counts are then obtained for each PG peak by dividing the net counts for that peak by N, which corrects the net counts of the PG peaks for total alpha activity, geometry, count time, and detector efficiency. A separate correction was applied to correct for differences in gamma-ray attenuation of the 414- and 662-keV peaks due to different container thicknesses. This was done by dividing $\mathrm{A}_{414}$ and $\mathrm{A}_{662}$ by their respective correction factors obtained with $e^{(\mu / \rho) \cdot(\rho x)}$, where $\mu / \rho$ is the mass attenuation coefficient for the container material, $\rho$ is the density of the container material, and $\mathrm{x}$ is the thickness of the container.

The normalized count data for the MIS items are shown in Table A-1. Data for four of the MIS items with PG and chemistry data have been excluded from this analysis. Removing these items ensures a data set with equivalent processing and counting conditions as the materials packaged in the 3013 containers. Two of the items $(011589 \mathrm{~A}$ and TS707001) were removed because high-efficiency detectors were used. These detectors were different than those used to perform the analysis on materials packaged in 3013 containers. The spectrum for as-received PuF4-1 was removed from the data set since the material had not been stabilized at $950{ }^{\circ} \mathrm{C}$. The MIS item (PuUOXBC05) was omitted since this material had not been blended like the other MIS items, and the processing history of this item is not well known.

Chemical analysis was performed on 10-g grab samples taken from as-received and calcined MIS items [4]. The analysis of $\mathrm{F}$ and $\mathrm{Cl}$ was done by ion chromatography, and the cations, which include $\mathrm{Al}, \mathrm{Be}, \mathrm{Mg}, \mathrm{K}$, and $\mathrm{Na}$, were measured by inductively coupled plasma atomic emission and mass spectroscopy. The chemical analysis data for the MIS items used in the calibration are shown in Table A-2.

\section{Method}

In our initial attempt to use the PG information quantitatively, we estimated detection limits for each of the elements sensitive to PG analysis. By using the detection limits, we would at least know the minimum amount of a particular impurity, such as $\mathrm{Cl}$, in a container. The PG data for the containers were sorted by count time and matched with the chemical analysis value. We determined a range for the detection limit of each element. The upper bound of this range is the concentration above which a reliable signal is always obtained with PG, and the lower bound is the highest concentration for which in almost all cases no signal is obtained with PG. The upper and lower bounds for each element are shown in Table 2. 
The MIS item showing the lowest concentration detected is shown in the last column. This value may be below the detection limit range. Those cases, which are indicated by asterisks $(*)$ may be due to uncertainty in chemical analysis data or increased contact between the impurity and the plutonium. As shown with the $\mathrm{Cl}$ data, longer count times improve the sensitivity, which lowers the detection limit range.

Table 2. Primary peak energies and detection limits for PG sensitive elements.

\begin{tabular}{|c|c|c|c|c|c|}
\hline \multirow{2}{*}{ Element } & $\begin{array}{c}\text { Primary } \\
\text { Energy }\end{array}$ & $\begin{array}{c}\text { Count } \\
\text { Time }\end{array}$ & \multicolumn{2}{|c|}{ Detection Limit Range (wt\%) } & Lowest Conc. Detected \\
\cline { 2 - 6 } & $\mathbf{( k e V )}$ & $\mathbf{( m i n )}$ & Lower Bound & Upper Bound & (wt\%) \\
\hline $\mathrm{Al}$ & 2236 & 60 & $\mathbf{0 . 3 5}$ & $\mathbf{0 . 5 5}$ & $0.31(\mathrm{MISNE} 4)^{*}$ \\
\hline $\mathrm{Be}$ & 4439 & 60 & $\mathbf{0 . 0 0 1 2}$ & $\mathbf{0 . 0 3 4}$ & $0.0006(07161856){ }^{*}$ \\
\hline $\mathrm{Cl}$ & 2167 & 600 & $\mathbf{0 . 1 6}$ & $\mathbf{0 . 3 9}$ & $0.39(07242201 \mathrm{~A})$ \\
\hline $\mathrm{Cl}$ & 2167 & 60 & $\mathbf{0 . 7 4}$ & $\mathbf{0 . 8 1 5}$ & $0.6(07032282 \mathrm{~A}){ }^{*}$ \\
\hline $\mathrm{Cl}$ & 2167 & 15 & $\mathbf{0 . 8 1 5}$ & $\mathbf{1 . 1}$ & $1.1(\mathrm{PuF} 4-1)$ \\
\hline $\mathrm{F}$ & 891,1274 & 60 & $\mathbf{0 . 0 6 1}$ & $\mathbf{0 . 0 9 1}$ & $0.091(\mathrm{MISNE})$ \\
\hline $\mathrm{F}$ & 2081 & 60 & $\mathbf{0 . 5 7}$ & $\mathbf{1 . 2}$ & $0.1(07161856){ }^{*}$ \\
\hline $\mathrm{Mg}$ & 1779,1273 & 60 & $\mathbf{0 . 0 8}$ & $\mathbf{0 . 1 7}$ & $0.17(07032282 \mathrm{~A})$ \\
\hline $\mathrm{Mg}$ & 2028 & 60 & $\mathbf{0 . 9 3}$ & $\mathbf{2 . 5 3}$ & $2.53(\mathrm{CO0024A})$ \\
\hline $\mathrm{P}$ & 2127 & 60 & $\mathbf{0 . 0 6}$ & $\mathbf{0 . 6}$ & $0.6(\mathrm{R}-437)$ \\
\hline $\mathrm{K}$ & 1524 & 60 & $\mathbf{1 . 7}$ & $\mathbf{1 . 8}$ & $1.12(\mathrm{MISNE})^{\star}$ \\
\hline $\mathrm{Na}$ & 1808 & 60 & No Data & $\mathbf{0 . 0 0 3}$ & $0.003(\mathrm{BLO}-39-11-14-004)$ \\
\hline
\end{tabular}

In addition to determining the minimum level of impurities, a trend analysis was performed to see if PG data can be used to predict chemistry data. The plots of chemistry versus normalized PG data for the MIS items do show a trend, e.g., increasing chemistry values as $\mathrm{PG}$ values increase. This trend is shown for $\mathrm{Cl}$ in Figure 1a. However, the linear regression line does not do a good job of predicting the chemistry data based on the PG data. There is considerable scatter in the concentration data, and it appears that there may be some curvature in the relationship between concentration and count rate. Therefore, a log-log transform was investigated to see if it might provide better linear calibration curves.

The plots of the transformed data for $\mathrm{Cl}$ are shown in Figure $1 \mathrm{~b}$. This transformation reduces and stabilizes the variability, providing a noticeably better fit to the points corresponding with low concentration. Overall, the transformation results in a better fit throughout the range of the data, and a similar effect was observed with the trends for the other elements. Therefore, we used the transformed data to construct all of the calibration plots. This transformation means that the relationship between the chemical concentration of container $i$ in ppm, $X_{\mathrm{i}}$, and the normalized count rate for the PG peak for container $i, N_{\mathrm{i}}$, can be described by

$$
\left[X_{i}\right]=b \cdot N_{i}{ }^{A} \text { multiplied by some random error }
$$

Taking the logs gives the linear equations used in the calibrations (3).

$$
\log \left[X_{i}\right]=A \cdot \log \left(N_{i}\right)+B \text { plus random error, where } B=\log (b) \text {. }
$$



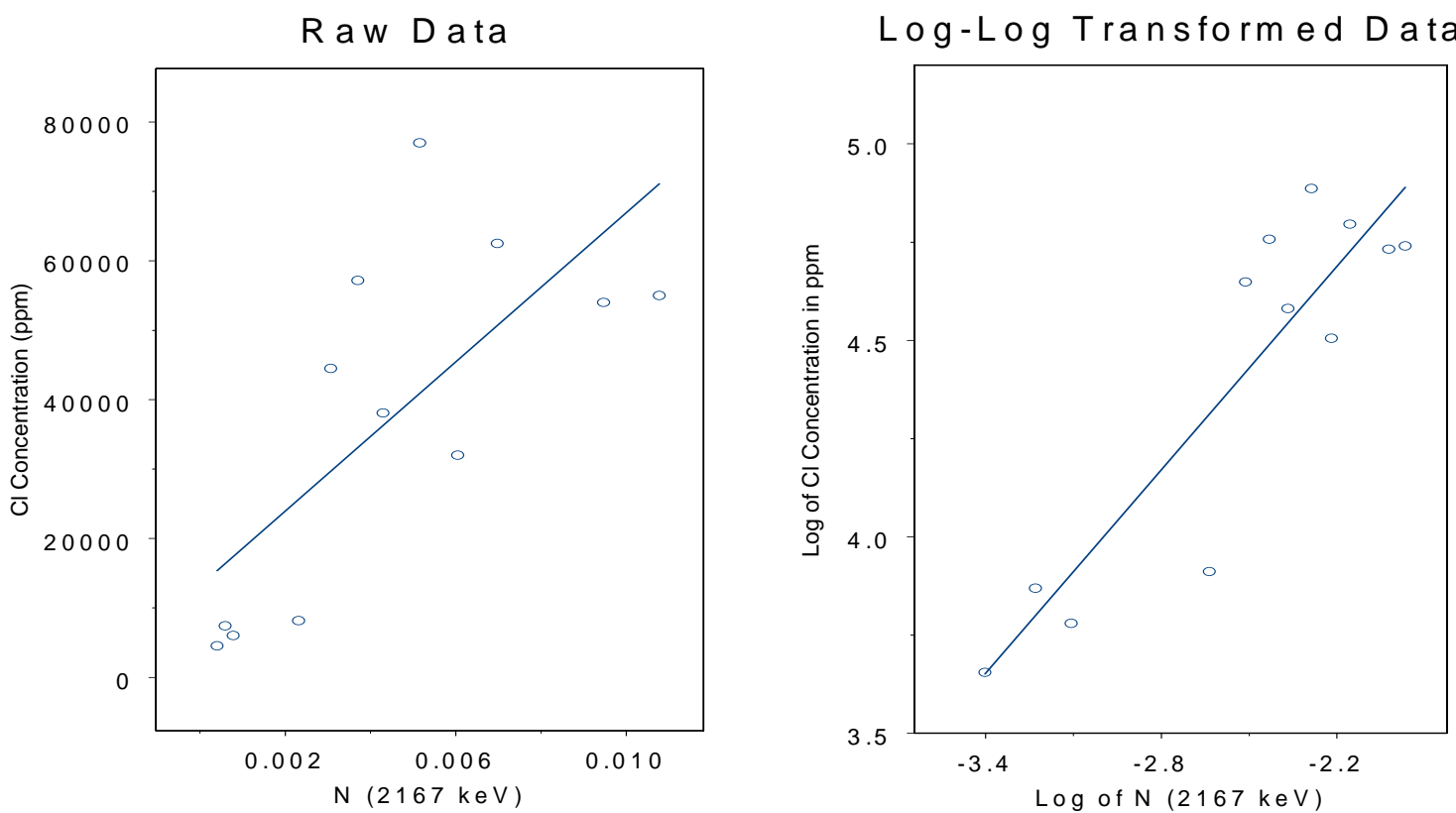

Figure 1. (a) Raw data of $\mathrm{Cl}$ concentration in $\mathrm{ppm}$ as a function of normalized count rate (left), (b) same data using log-log transform (right).

\section{Results and Discussion}

The results of the linear calibration with the transformed chemistry data for $\mathrm{Al}, \mathrm{Be}, \mathrm{Cl}, \mathrm{F}$, $\mathrm{Mg}, \mathrm{Na}$ are shown in Figures $2 \mathrm{a}-\mathrm{f}$ along with the $95 \%$ confidence intervals for the calibration curves. These curves are the linear regression fits to the data. (Note that residual quantile plots were consistent with the assumption of normality of the transformed data.) We were unable to construct a calibration with $\mathrm{K}$ due to low sensitivity and the limited concentration range above the detection limit. Each of the calibration curves was evaluated using plots of the residuals versus fit and response versus fit shown in Appendix B. The residuals plot shows the difference between each of the data points and the fit line, and the differences should be randomly distributed around zero. The response versus fit plot compares the predicted and actual values, and should have a slope of approximately one.

The parameters $A$ and $B$ are the slope and intercept of the calibration line. These parameters along with the $\mathrm{R}^{2}$ and $p$-values for each of the calibrations are shown in Table 3. The $\mathrm{R}^{2}$ value shows the proportion of the variance in the log chemistry data that is removed by conditioning on the log PG data. The $p$-value is obtained from an F-test that compares the linear regression model to a simple model that only has the $B$ term (the model that uses the overall mean of the log chemistry data as the predictor). This test can be thought of as a test for the importance of the slope or linear term. The $p$-values should be less than 0.05 to show there is only a $5 \%$ chance or less that the linear term is not important. 
The calibrations were constructed using only MIS item data from materials stabilized at $950{ }^{\circ} \mathrm{C}$; Table 3 shows the range of concentration in wt $\%$ and the range of $\mathrm{N}$ covered by this data set. Box plots in Appendix $\mathrm{C}$ compare the range of $\mathrm{N}$ for the MIS data at LANL with the ranges of $\mathrm{N}$ for materials in 3013 containers from other sites. The shaded boxes contain the middle $50 \%$ of the data, and the line in the center of the box represents the median of the data set. The "whiskers" extending from the boxes are $1.5 \times$ the length of the box. Data values beyond these whiskers could be outliers and should be examined as different than the bulk of the data. In numerous cases, the data from other sites extend beyond the range of the MIS data especially at the high end. We must be careful when using the linear model to predict values beyond the range of the data because of the possibility that other factors affecting the trend make a nonlinear relationship. For instance, it is possible that the PG signal could actually decrease at very high impurity concentrations because the alpha particle source diminishes, and the contact between the impurities and the $\mathrm{Pu}$ decreases with low Pu content. However, we are providing a relative ranking or grouping of concentrations rather than accurate prediction, and we felt extrapolation is appropriate for these applications.

Table 3. Calibration parameters

\begin{tabular}{|c|c|c|c|c|c|c|}
\hline Element & $\mathbf{A}$ & $\mathbf{B}$ & $\mathbf{R}^{2}$ & $\mathbf{p}$ & $\begin{array}{c}\text { Range of N for } \\
\text { MIS Samples }\end{array}$ & $\begin{array}{c}\text { Concentration Range } \\
\text { for MIS Samples }\end{array}$ \\
\hline $\mathrm{Al}$ & 0.478 & 4.823 & 0.684 & $4.3 \mathrm{E}-02$ & $0.001-0.04$ & $0.18-1.2 \mathrm{wt} \%$ \\
\hline $\mathrm{Be}$ & 0.813 & 4.527 & 0.924 & $9.2 \mathrm{E}-03$ & $0.003-0.06$ & $0.034-0.48 \mathrm{wt} \%$ \\
\hline $\mathrm{Cl}$ & 0.864 & 6.589 & 0.806 & $7.4 \mathrm{E}-05$ & $0.0004-0.01$ & $0.45-7.7 \mathrm{wt} \%$ \\
\hline $\mathrm{F}$ & 1.029 & 5.870 & 0.911 & $6.3 \mathrm{E}-05$ & $0.0008-0.16$ & $0.09-19 \mathrm{wt} \%$ \\
\hline $\mathrm{Mg}$ & 1.567 & 7.051 & 0.823 & $7.5 \mathrm{E}-06$ & $0.0002-0.074$ & $0.002-31 \mathrm{wt} \%$ \\
\hline $\mathrm{Na}$ & 1.313 & 5.696 & 0.854 & $3.2 \mathrm{E}-10$ & $0.0015-0.15$ & $0.003-2.4 \mathrm{wt} \%$ \\
\hline
\end{tabular}



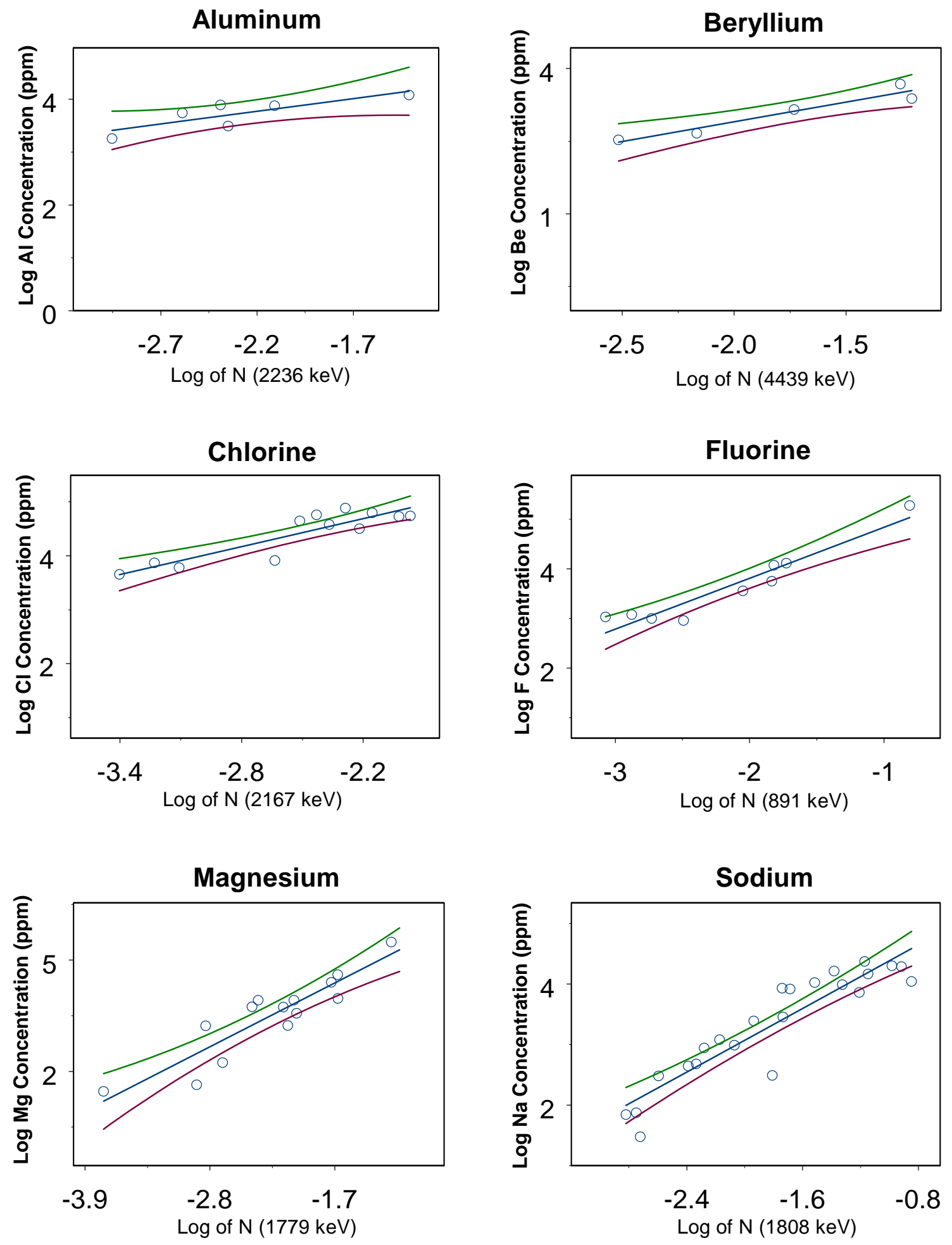

Figure 2. Calibration plots for (a) Al, (b) Be, (c) Cl, (d) F, (e) Mg, and (f) Na. 


\section{Aluminum Calibration}

The Al calibration had the highest $p$-value of 0.043 and the lowest $\mathrm{R}^{2}$ value of 0.68 , however, this is statistically significant based on a $95 \%$ confidence level. The small sample size, data variability, and small slope contribute to the uncertainty in the model. The response versus fit plot (Figure B-1) shows reasonable prediction (for the purpose of ordering or ranking) with some deviation, and the residuals plot (Figure B2) shows no trend. The box plots for $\mathrm{N}_{2236 \mathrm{keV}}$ (Figure $\mathrm{C}-1$ ) show good coverage of the Hanford, RFETS, and SRS data sets by MIS data, but predictions for the LLNL data will be based on extrapolation.

This calibration has been used to predict the Al concentrations for certain materials having chemical analysis data from Hanford, SRS, and LANL. These materials include Hanford input items (measured prior to stabilization and packaging), Hanford 3013 containers, and SRS 3013 containers. From the results in Figure 3, the calibration overpredicts below 2,000 ppm and underpredicts above this value. The result from MIS item 011589A measured on a high-efficiency detector shows good agreement with the measured $\mathrm{Al}$ concentration. Based on this data, it is uncertain whether extrapolation of the Al calibration outside of the range of MIS data would give accurate results.

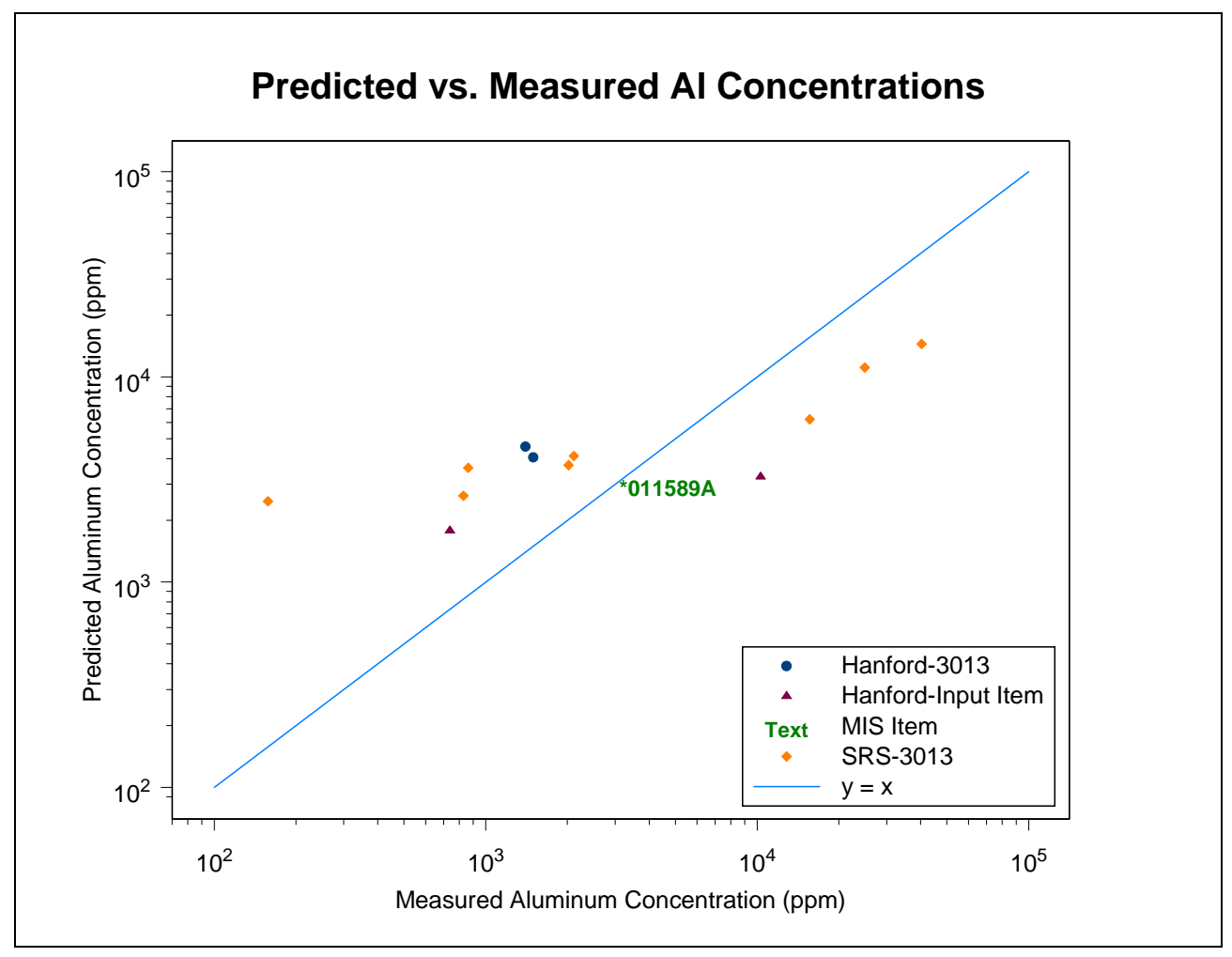

Figure 3. Comparison of Al predictions with measured data.

\section{Beryllium Calibration}

The Be calibration was constructed using only a few data points. There is very little deviation from the calibration curve giving a high $\mathrm{R}^{2}$ value. The linear model has high significance as shown by the low $p$-value of 0.0092. Although the sample size is small, 
good results would be expected for Be since this element is usually not associated with salts and heterogeneous material, so sampling error in the chemistry measurement would be smaller. In addition, this element has the lowest threshold energy for reaction with alpha-particles, which increases the overall sensitivity of this element to PG. The response versus fit plot (Figure B-3) shows accurate prediction, and the residuals plot shows no overall trend. The data range for Be in MIS items as shown by the box plot for $\mathrm{N}_{4439 \mathrm{keV}}$ (Figure C-2) is small compared with RFETS and LLNL, so many of the predictions from these sites will be based on extrapolation. However, the correlation in this model is deemed strong enough to provide reasonable relative ranking of canisters in the range of data required.

This calibration has been used to predict the Be concentrations for certain materials having chemical analysis data from Hanford and SRS. These materials include Hanford input items (measured prior to stabilization and packaging), Hanford 3013 containers, and SRS 3013 containers. The results for the Hanford input items and SRS 3013 containers in Figure 4 show relatively good agreement between the predicted and the measured Be concentrations. Therefore, we expect the large difference in the data point for the Hanford 3013 container is due to sampling error in obtaining the analytical chemistry results.

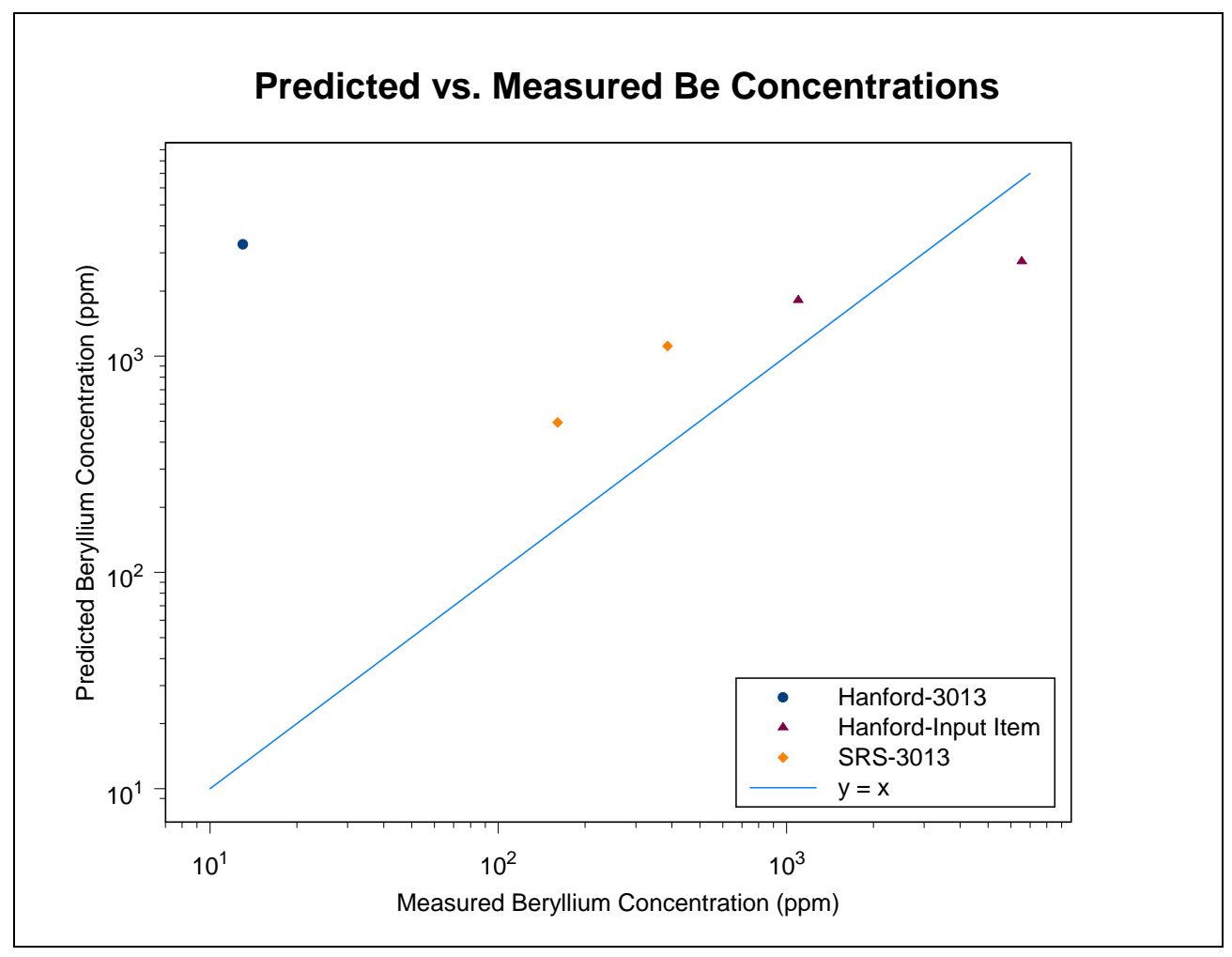

Figure 4. Comparison of Be predictions with measured data. 


\section{Chlorine Calibration}

The linear term in the $\mathrm{Cl}$ calibration has high significance as shown by the low $p$-value of $7.4 \times 10^{-5}$, which is due to the large sample size and small deviations from the calibration curve. The calibration also has a high degree of variance reduction as shown by the $\mathrm{R}^{2}$ value. The response versus fit plot (Figure B5) shows relatively good prediction with some deviation. The residuals plot shows some larger residuals at higher concentrations, but they are distributed about zero. The data range for $\mathrm{Cl}$ in MIS items as shown by the box plot for $\mathrm{N}_{2167 \mathrm{keV}}$ (Figure C-3) is lower compare with other sites, so many of the predictions will be based on extrapolation. The correlation in this model is deemed strong enough to provide reasonable relative ranking of canisters for $\mathrm{Cl}$ in the range of data required.

This calibration has been used to predict the $\mathrm{Cl}$ concentrations for certain materials having chemical analysis data from Hanford, SRS, and LANL. These materials include Hanford input items (measured prior to stabilization and packaging), Hanford 3013 containers, and SRS 3013 containers. The predictions above 55,000 ppm were based on extrapolation. Overall, the results in Figure 5 show good agreement between the predicted and measured $\mathrm{Cl}$ data, and the data support using the calibration beyond the range of MIS data (at least to concentrations of $10 \mathrm{wt} \% \mathrm{Cl}, \mathrm{N}_{2167 \mathrm{keV}}=0.21$ ). As shown by the Hanford input item at $20 \mathrm{wt} \%$, large residuals may be possible. The large discrepancy in the TS707001 data point may be due to sampling error in analytical chemistry. The as-received chloride concentration was measured at $0.2 \mathrm{wt} \%$, and this value may be more accurate although the material was calcined prior to the PG measurement. 


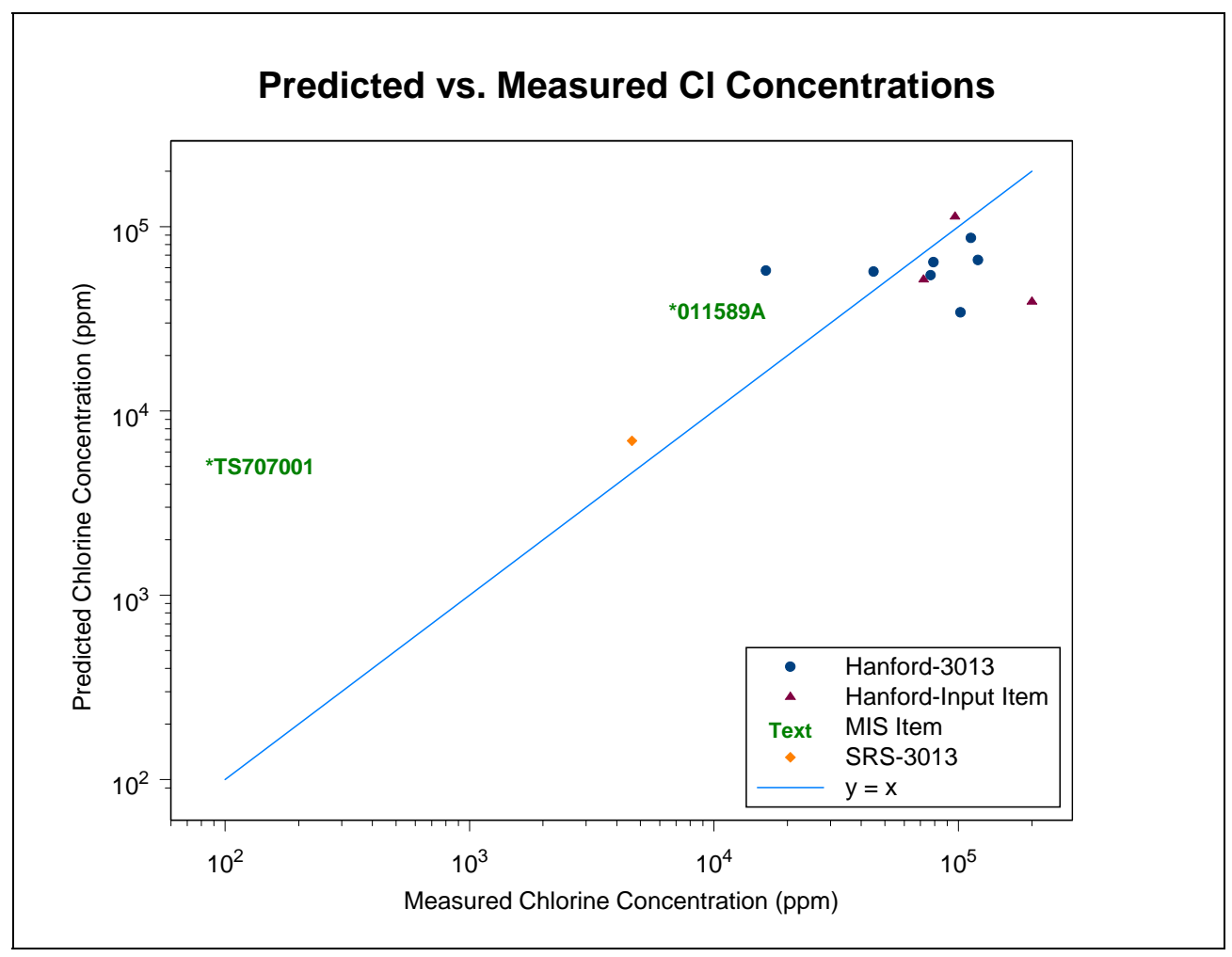

Figure 5. Comparison of $\mathrm{Cl}$ predictions with measured data.

A calibration was previously developed by Fazzari, Jones, and Delegard at Hanford to predict chloride concentrations in Rocky Flats materials at Hanford [7]. This calibration was used as a screening tool for electrorefining (ER) materials, which were processed using a low temperature $\left(750{ }^{\circ} \mathrm{C}\right)$ stabilization to reduce equipment damage. This calibration calculates the weight percent of chloride using the net count rate of the $2167-\mathrm{keV}$ peak $\mathrm{C}_{2167 \mathrm{keV}}$, the mass of plutonium $\mathrm{M}_{\mathrm{Pu}}$, and the net weight of the material $\mathrm{M}_{\mathrm{Net}}$ as shown in (4). The detector-specific calibration factor, $K$, must be determined experimentally.

$$
\mathrm{Cl} \%=C_{2167 \mathrm{keV}}[\mathrm{cts} / \mathrm{sec}] \cdot \frac{1}{K}\left[\frac{\mathrm{g} \mathrm{Pu} \cdot \mathrm{g} \mathrm{Cl}}{\text { counts }}\right] \cdot \frac{1}{M_{P_{u}}[\mathrm{~g}]} \cdot \frac{1}{M_{\text {Net }}[\mathrm{g}]} \cdot 100 \%
$$

A comparison between the LANL and Hanford calibrations for three Hanford chloride standards is shown in Table 4. The Hanford calibration shows good agreement between the predicted and measured chloride concentrations through $20 \mathrm{wt} \%$ for all three standards. The LANL calibration shows good agreement for the standards less than $10 \mathrm{wt} \%$ chlorine, but it appears that accuracy is lost above $10 \mathrm{wt} \%$. The difference is likely due to the low plutonium content of this sample, which results in a reduced alphaparticle production rate. Therefore, we cannot assume that our calibration curve remains linear beyond $10 \mathrm{wt} \% \mathrm{Cl}$. The Hanford calibration accounts for the low plutonium content by using the mass of plutonium in the calibration. 
Table 4. Comparison of Hanford and LANL calibrations

\begin{tabular}{|c|c|c|c|c|}
\hline $\begin{array}{c}\text { Input Item } \\
\text { Pu\% }\end{array}$ & $\begin{array}{c}\text { Meas. Cl \% } \\
\text { (Hanford) }\end{array}$ & $\begin{array}{c}\text { Pred. Cl\% } \\
\text { (LANL) }\end{array}$ & $\begin{array}{c}\text { Pred. Cl\% } \\
\text { (Hanford) }\end{array}$ \\
\hline ARF-102-86-387 & $53.0 \%$ & 7.2 & 5.2 & 7.6 \\
\hline PPSL-518 & $69.1 \%$ & 9.7 & 11.4 & 6.1 \\
\hline ARF-102-85-185-5 & $26.1 \%$ & 20 & 3.9 & 17.1 \\
\hline
\end{tabular}

However, note that the Hanford calibration does not account for ${ }^{241}$ Am content.

Neglecting this term could result in substantial errors because the alpa-particle production from ${ }^{241} \mathrm{Am}$ is not accounted for. Therefore, application of the Hanford calibration is limited to specific detectors and materials of the same age since the ${ }^{241}$ Am would be the same.

\section{Fluorine Calibration}

The linear term in the F calibration also has high significance as shown by the low $p$-value of $6.3 \times 10^{-5}$, which is due to the large range of data and small amount of scatter in the middle range of data. The calibration also has a high degree of variance reduction as shown by the $\mathrm{R}^{2}$ value, and the response versus fit plot (Figure B-7) shows relatively good prediction. The residuals plot (Figure B-8) shows more positive residuals at the high and low ends of the data set. The box plot for $\mathrm{N}_{891 \mathrm{keV}}$ (Figure C-4) shows good coverage of the middle $50 \%$ of the data across the sites. Based on data from MIS item PuF4-1C, the calibration curve is linear up to $19 \mathrm{wt} \% \mathrm{~F}$. Predictions for F concentrations higher than $19 \mathrm{wt} \%$, although unusual, will be based on extrapolation. The correlation in this model is deemed strong enough to provide reasonable relative ranking of containers for $\mathrm{F}$ in the range of data required.

This calibration has been used to predict the F concentrations for certain materials having chemical analysis data from Hanford, SRS, and LANL. These materials include Hanford input items (measured prior to stabilization and packaging), Hanford 3013 containers, and SRS 3013 containers. The predicted and measured F concentrations for the SRS 3013 and the MIS samples (Figure 6) show good agreement, but the Hanford predictions tend to be lower than the measured values. The item with the highest F concentration is MIS item PuF4-1. The concentration of $\mathrm{F}$ in the as-received material was $16 \mathrm{wt} \%$, and the predictions show good agreement even at the high end. It is uncertain whether extrapolation is possible beyond the range of MIS data, but this situation is considered unlikely based on the 3013 data analyzed. 


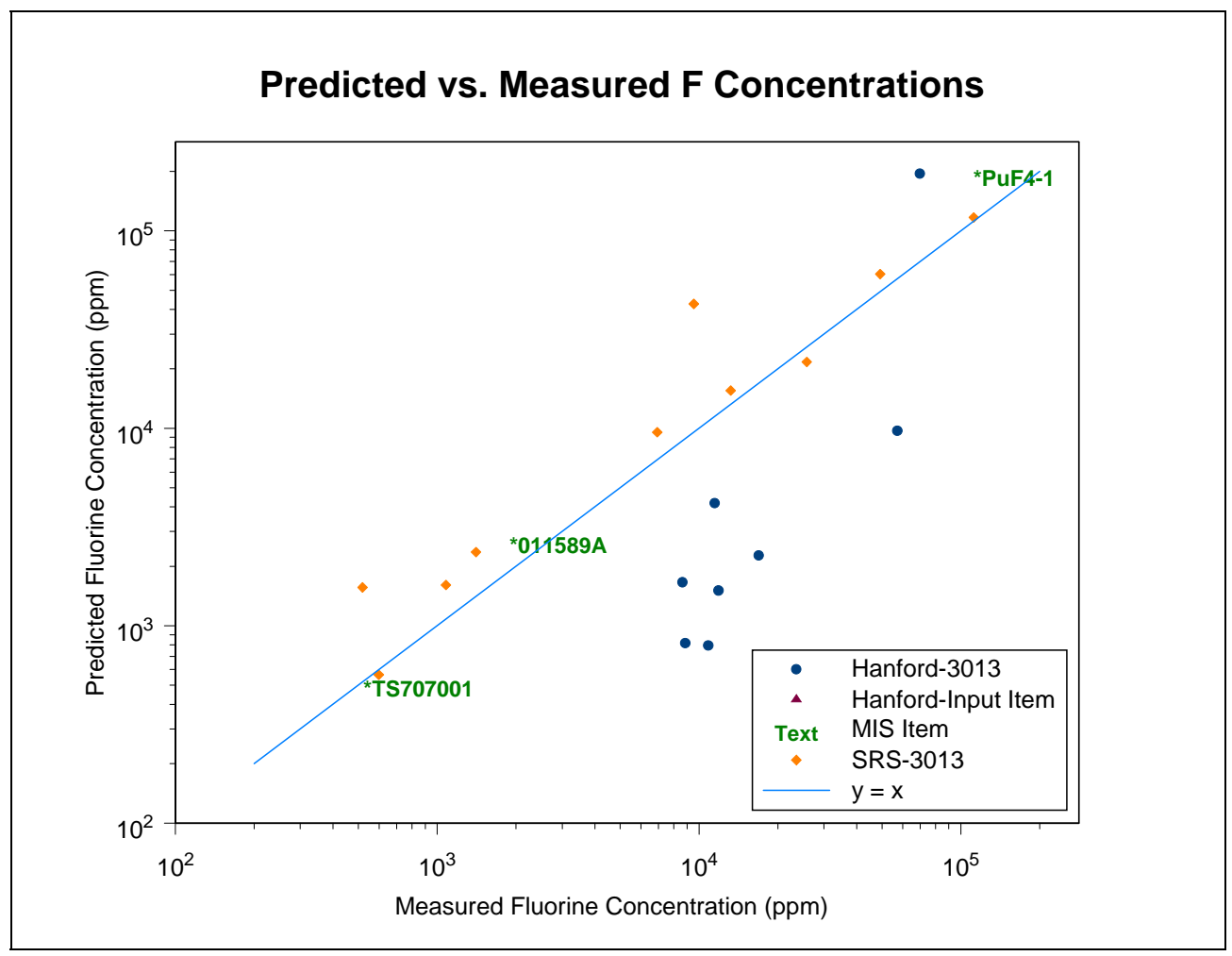

Figure 6. Comparison of $F$ predictions with measured data.

\section{Magnesium Calibration}

The Mg calibration has a large amount of scatter about the calibration curve, and seven of the points are outside of the $95 \%$ confidence band. The scatter is likely due to the $\mathrm{Mg}$ existing in different types of chemical compounds, which achieve different levels of the intimate mixing with the plutonium. It would be expected that $\mathrm{Mg}$ in the chloride salt achieves intimate mixing with the plutonium, but sampling error in analytical chemistry would be high because of the large solid chunks present in the material. Magnesium found in relatively pure material in the form of $\mathrm{MgO}$ may not achieve intimate mixing with the plutonium, but the material is more homogeneous having a smaller sampling error in the chemistry measurement. Overall, the response vs. fit plot (Figure B-9) shows good agreement at all $\mathrm{Mg}$ concentrations, and the residuals plot (Figure B-10) shows no overall trend. The box plot for $\mathrm{N}_{1779 \mathrm{kev}}$ (Figure C-5) shows good coverage of the middle $50 \%$ of the data across the sites. The large number of extreme values corresponds with materials from the $\mathrm{Mg}(\mathrm{OH})_{2}$ precipitate process, and many of these predictions will be based on extrapolation. The correlation in this model is deemed strong enough to provide reasonable relative ranking of containers for $\mathrm{Mg}$ in the required data range.

This calibration has been used to predict the Mg concentrations for certain materials having chemical analysis data from Hanford, SRS, and LANL. These materials include Hanford input items (measured prior to stabilization and packaging), Hanford 3013 containers, and SRS 3013 containers. Most of these materials contain chloride salts, which are expected to have poor mixing, and the scatter in the data (Figure 7) may be due 
to both sampling error and differences in mixing. The best results were obtained with the Hanford 3013 data.

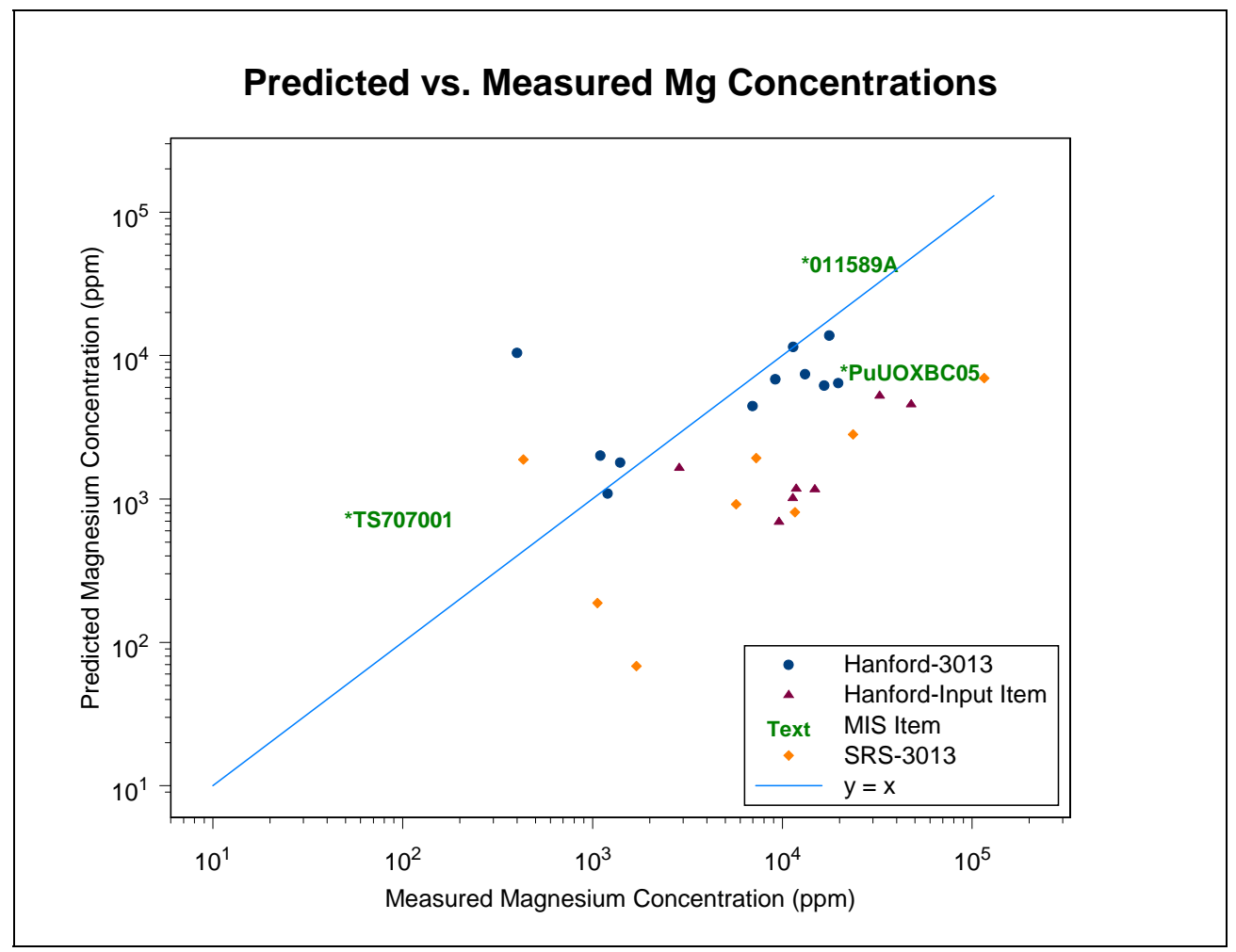

Figure 7. Comparison of Mg predictions with measured data.

\section{Sodium Calibration}

The Na calibration has the lowest $p$-value of all the calibrations showing high significance in the linear term. However, this data set has a high degree of scatter with 10 of 21 data points outside of the $95 \%$ confidence band. Like $\mathrm{Mg}, \mathrm{Na}$ has been detected in both relatively pure and impure materials, in which different levels of intimate mixing are achieved. The response vs. fit plot (Figure B-11) shows about $0.3 \mathrm{wt} \%$ underprediction for mid to high $\mathrm{Na}$ concentration, and the residuals plot (Figure B-12) shows more positive residuals but no overall trend. To reduce the scatter, we could consider removing the two points positioned well below the curve. However, this is not justified based on the available data, and for the purposes of ranking the levels of $\mathrm{Na}$, this was not done. The box plot for $\mathrm{N}_{1808 \mathrm{keV}}$ (Figure C-6) shows reasonable coverage of the middle $50 \%$ of the data across the sites. The correlation in this model is deemed strong enough to provide reasonable relative ranking of containers for $\mathrm{Na}$ in the required data range.

This calibration has been used to predict the Na concentrations for certain materials having chemical analysis data from Hanford, SRS, and LANL. These materials include Hanford input items (measured prior to stabilization and packaging), Hanford 3013 containers, and SRS 3013 containers. The results in Figure 8 show good agreement 
between the predicted and measured $\mathrm{Na}$ concentrations for the full range of data, and the scatter may be attributed to sampling errors.

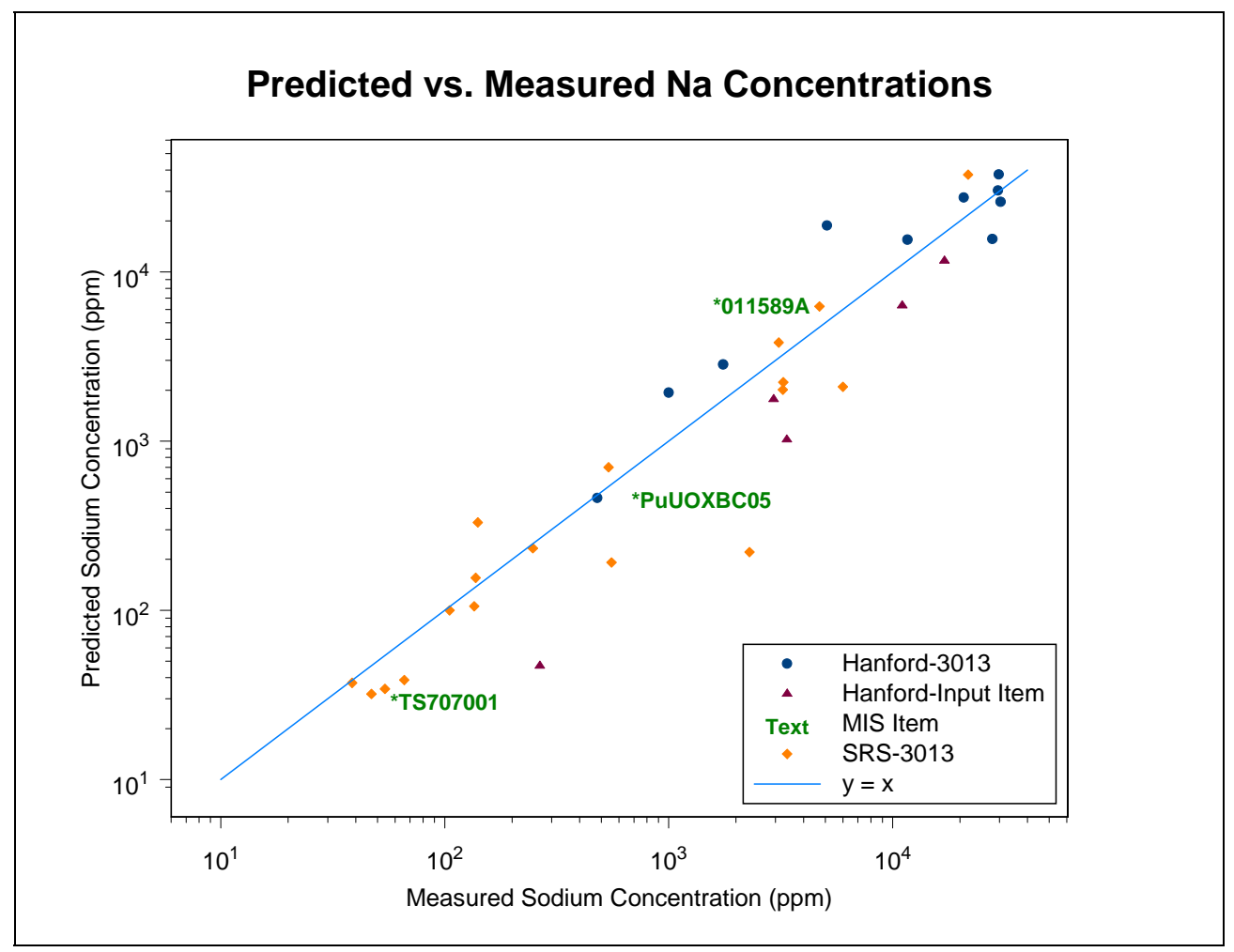

Figure 8. Comparison of Na predictions with measured data.

\section{Errors in Predictions}

The errors associated with the calibrations come from several sources, most of which cannot be quantified; caution should be used when interpreting the results of the calibration. The quantifiable errors are measurement errors due to gamma-ray counting uncertainty and error in concentration measurement, but we assume that these errors do not have a large impact on the overall results. The errors having the largest effect on the results are due to sample nonhomogeneity, which affects both the intimate mixing of the sample and our ability to obtain a representative grab-sample for chemical analysis. Nonhomogeneity, which varies from sample to sample, cannot be measured with these data.

Data from Foster's experiment have been used to illustrate the effects from intimate mixing of impurities and plutonium independent of sampling errors [4]. Samples have been prepared by adding known quantities of $\mathrm{NaCl}, \mathrm{KCl}$, and $\mathrm{CaF}_{2}$ to pure $\mathrm{PuO}_{2}$. The materials were blended, and an initial PG spectrum was taken. The material was then blended and stabilized by heating at $600{ }^{\circ} \mathrm{C}, 800{ }^{\circ} \mathrm{C}$, and $950{ }^{\circ} \mathrm{C}$, with $\mathrm{PG}$ spectra measured following each stabilization. The calibration curves were used to predict the concentrations of $\mathrm{Cl}, \mathrm{F}$, and $\mathrm{Na}$ in the samples. 
The actual and predicted impurity concentrations are shown in Table 5. The results for F were consistent regardless of the calcination, which shows that intimate mixing was achieved by blending alone. The decrease in predicted concentration as the material was stabilized may be due to competition for alpha-particles as the chloride salt achieves better contact with the plutonium. The predicted concentrations of chlorine and sodium increased dramatically as the melting point of the salts was reached during the stabilization at $800{ }^{\circ} \mathrm{C}$, which shows how the molten salt achieves intimate contact with the plutonium. The intimate contact between the plutonium and the salt is required to both detect and quantify these impurities, and it is achieved when the material is calcined at $800{ }^{\circ} \mathrm{C}$ or higher.

Table 5. PG Results from a $\mathrm{PuO}_{2}$-Salt mixture prepared and calcined at various temperatures

\begin{tabular}{|c|c|c|c|}
\hline & Predicted $\mathrm{Cl} \%$ & Predicted F\% & Predicted $\mathrm{Na} \%$ \\
\hline As-Received & -- & 6.5 & 0.03 \\
\hline Stabilized at $600^{\circ} \mathrm{C}$ & 0.2 & 6.5 & 0.05 \\
\hline Stabilized at $800^{\circ} \mathrm{C}$ & 4.2 & 5.2 & 1.72 \\
\hline Stabilized at $950^{\circ} \mathrm{C}$ & 3.9 & 4.8 & 1.77 \\
\hline & $\begin{array}{c}\text { Actual [Cl]: } \\
5 \text { wt\% in } \\
\text { as-received sample }\end{array}$ & $\begin{array}{c}\text { Actual [F]: } \\
5 \text { wt\% in } \\
\text { as-received sample }\end{array}$ & $\begin{array}{c}\text { Actual [Na]: } \\
1.8 \text { wt } \% \text { in } \\
\text { as-received sample }\end{array}$ \\
\hline
\end{tabular}

Based on our results, we expect PG to reliably identify the impurities materials stabilized at $950{ }^{\circ} \mathrm{C}$. Although there is no way to guarantee that intimate mixing is achieved, we expect to obtain reasonable predictions of impurity concentrations within the range of MIS data. Because of the potentially large errors associated with the results, the predicted concentrations should be treated only as semiquantitative estimates.

\section{Application of PG to Integrated Surveillance Program}

To apply this technique to judgmental sampling, the predictions can be used to provide order-of-magnitude approximations, to assign containers to a concentration range or group the containers for the purpose of relative ranking. The concentration ranges may be set arbitrarily or assigned based on the distributions of impurities shown in Appendix D. For example, many of these distributions, such as $\mathrm{Cl}$ and $\mathrm{Mg}$, have multiple clusters of containers at certain concentrations, and these clusters could be used to set a low-, mid-, and high-concentration ranges. An example of how this technique could be applied is shown in Table 6, where the containers could be identified as high concentration, mid concentration, or low concentration for a given element. 
Table 6. Concentration ranges based on predicted concentration distributions

\begin{tabular}{|c|c|c|c|}
\hline Element & Low-Concentration & Mid-Concentration & High-Concentration \\
\hline $\mathrm{Al}$ & $<10,000 \mathrm{ppm}$ & $\mathrm{N} / \mathrm{A}$ & $>10,000 \mathrm{ppm}$ \\
\hline $\mathrm{Be}$ & $<1,000 \mathrm{ppm}$ & $\mathrm{N} / \mathrm{A}$ & $>1,000 \mathrm{ppm}$ \\
\hline $\mathrm{Cl}$ & $<20,000 \mathrm{ppm}$ & $20,000-90,000 \mathrm{ppm}$ & $>90,000 \mathrm{ppm}$ \\
\hline $\mathrm{F}$ & $<8,000 \mathrm{ppm}$ & $8,000-90,000 \mathrm{ppm}$ & $>90,000 \mathrm{ppm}$ \\
\hline $\mathrm{Mg}$ & $<10,000 \mathrm{ppm}$ & $10,000-50,000 \mathrm{ppm}$ & $>50,000 \mathrm{ppm}$ \\
\hline $\mathrm{Na}$ & $<5,000 \mathrm{ppm}$ & $5,000-16,000$ & $>16,000 \mathrm{ppm}$ \\
\hline
\end{tabular}

Currently in the binning process, any positive PG results for chlorine forces the item into the corrosive category since chloride salts and moisture are expected to be the leading cause of stress corrosion cracking and pitting. The predicted chloride concentration ranges are used to show the degree to which chloride containers are sampled for surveillance within each bin by the number of high, mid, and low $\mathrm{Cl}$ concentrations in the sample. The involvement of $\mathrm{F}$ in stress corrosion cracking and pitting is unknown, so containers with $\mathrm{F}$ may be at risk for pressurization and corrosion. To prevent dilution of the corrosive bin however, only items with mid and high $\mathrm{F}$ concentrations were placed in the corrosive category. It is expected that these containers would have the greatest risk of the fluoride group, and that any problems associated with $\mathrm{F}$ would be observed in these containers. The remaining elements, $\mathrm{Na}, \mathrm{K}, \mathrm{Mg}$, and $\mathrm{Be}$, are used to make engineering judgment decisions. In cases where PG data are unavailable for a particular item, trends within a particular group of materials from similar processes are used to predict the conditions in the unknown container.

\section{Conclusion}

Linear calibrations to predict the concentration of $\mathrm{Al}, \mathrm{Be}, \mathrm{Cl}, \mathrm{F}, \mathrm{Mg}$, and $\mathrm{Na}$ in plutonium oxide stored in 3013 containers were constructed using the PG normalized count rate and chemical assay data from the MIS items. The scatter present in the data was reduced and the variance was stabilized using a log-log transform. The scatter is likely a combination of several factors including sample geometry, error in sampling for chemical assay, statistical counting error, and intimacy of mixing of impurities and plutonium. Of these factors, mixing and sampling are expected to have the largest influence on the results. The mixing is affected by the types of impurities in the material, the processing, and the calcination temperature, which affects both the PG signal and the chemical assay results due to the nonhomogeneity of the grab samples obtained. As a result, the concentration values obtained from the calibration have considerable uncertainties associated with them. Despite the many sources of error, the transformed PG data show strong correlation with the transformed chemistry data. The PG and chemistry data from materials at other sites measured under similar conditions show good agreement with the calibration curves based on MIS data. Based on the strength of these correlations, we expect that the calibrations can be used to provide reasonable semiquantitative rankings or groupings of the impurity concentrations in the 3013 containers for the purpose of selecting items for judgmental sampling. 


\section{References}

1. Horrell, D. R., Dodson, K., et al. "Integrated Surveillance Program in Support of Long-Term Storage of Plutonium-Bearing Materials," Los Alamos National Laboratory, Los Alamos, NM 87545. LA-UR-00-3246 (March 2001).

2. Peppers, L. G., Kelly, E. J., et al. “3013 Containers Selected for Non Destructive Evaluation (NDE) in FY 2005." Los Alamos National Laboratory, Los Alamos, NM 87545. LA-UR-05-2193 (March 2005).

3. Mason, R. E, Allen, T., et al. Materials Identification and Surveillance: June 1999 Characterization Status Report. Los Alamos National Laboratory, Los Alamos, NM 87545. LA-UR-99-3053 (June 1999).

4. Foster, L. A., Rennie, J. A, and Mason, R. E., "Characterization of Plutonium Oxides by Alpha-Induced PG-Ray Analysis. Los Alamos National Laboratory, Los Alamos, NM 87545. LA-UR-02-3408.

5. McKibben, J. M. Reaction gammas for analysis of impurities in alpha emitters. Nuclear Applications 4(1968): 260.

6. Martin, R. H., Reaction gamma rays in plutonium compounds, mixtures, and alloys. Dow Chemical, USA, Rocky Flats Division, Golden, CO. RFP-2382 (June 1975).

7. Fazzari, D. M, Jones, S. A., and Delegard, C. H. Application of prompt gammaray analysis to identify electrorefining salt-bearing plutionium oxide at the plutonium finishing plant. Pacific Northwest National Laboratory, Richland, Washington. PNNL-14409 (September 2003). 
Appendix A

\section{Prompt Gamma and Chemistry Results}


Table A-1. Prompt gamma normalized count data for the respective $\mathrm{Al}, \mathrm{Be}, \mathrm{Cl}, \mathrm{F}, \mathrm{Mg}, \mathrm{K}$, and Na peaks for the MIS items ${ }^{1}$

\begin{tabular}{|c|c|c|c|c|c|c|c|}
\hline MIS Item Name & $\mathrm{N}_{2236 \mathrm{keV}}$ & $\mathrm{N}_{4439 \mathrm{keV}}$ & $\mathrm{N}_{2167 \mathrm{keV}}$ & $\mathrm{N}_{891 \mathrm{keV}}$ & $\mathrm{N}_{1779 \mathrm{keV}}$ & $\mathrm{N}_{1524 \mathrm{keV}}$ & $\mathrm{N}_{1808 \mathrm{keV}}$ \\
\hline 053038 & $4.075 E-03$ & 3.037E-03 & $3.070 \mathrm{E}-03$ & $1.462 \mathrm{E}-02$ & 4.220E-03 & & $1.422 \mathrm{E}-01$ \\
\hline 669194 & & $6.220 \mathrm{E}-02$ & & & & & 8.486E-03 \\
\hline 5501407 & & 6.810E-03 & & & 1.830E-04 & & $1.785 \mathrm{E}-03$ \\
\hline \multicolumn{8}{|l|}{5501579} \\
\hline 07161856 & & 5.763E-03 & & 1.864E-03 & & & 4.075E-03 \\
\hline $07032282 A$ & $1.115 \mathrm{E}-03$ & & 7.795E-04 & $1.512 \mathrm{E}-02$ & $1.450 \mathrm{E}-03$ & & $1.154 \mathrm{E}-02$ \\
\hline $07242165 A$ & & & & & 1.210E-03 & & 6.706E-03 \\
\hline ARF-102-85-114-1 & & 1.852E-02 & & & & & $5.257 \mathrm{E}-03$ \\
\hline ARF-102-85-223 & & & 1.078E-02 & & 7.029E-03 & 8.694E-03 & $7.108 \mathrm{E}-02$ \\
\hline ARF-102-85-295 & $2.585 E-03$ & & 5.154E-03 & $1.852 \mathrm{E}-02$ & 2.107E-02 & 3.776E-03 & $6.734 \mathrm{E}-02$ \\
\hline ARF-102-85-355 & & & 5.895E-04 & $8.897 \mathrm{E}-03$ & $2.051 \mathrm{E}-03$ & & $1.553 \mathrm{E}-02$ \\
\hline ARF-102-85-365 & & & 4.289E-03 & 8.480E-04 & 3.722E-03 & 4.113E-03 & $4.152 \mathrm{E}-02$ \\
\hline BLO-39-11-14-004 & & & & & & & 1.897E-03 \\
\hline C00024A & & 5.540E-02 & $2.311 E-03$ & & $2.118 E-02$ & & $3.046 \mathrm{E}-02$ \\
\hline CLLANL025 & & & 3.706E-03 & & 9.161E-03 & 1.198E-02 & $4.715 \mathrm{E}-02$ \\
\hline MISNE4 & 4.464E-03 & & 6.043E-03 & 3.217E-03 & $1.859 \mathrm{E}-02$ & 5.867E-03 & $6.195 \mathrm{E}-02$ \\
\hline MT1490 & & & & & & & $2.540 \mathrm{E}-03$ \\
\hline PBO-47-09-012-023 & & & & & & & 1.513E-03 \\
\hline PMAXBS & & & 9.472E-03 & & & $3.325 E-03$ & $1.209 \mathrm{E}-01$ \\
\hline PuF4-1 & & & & $1.554 \mathrm{E}-01$ & 1.802E-02 & & \\
\hline$R-437$ & 1.300E-02 & & & & 7.399E-02 & & $2.059 \mathrm{E}-02$ \\
\hline $\mathrm{R}-438$ & 7.782E-03 & & & 1.325E-03 & $6.247 \mathrm{E}-02$ & & 1.815E-02 \\
\hline SCP711-46 & & & & & & & $4.626 \mathrm{E}-03$ \\
\hline
\end{tabular}

\footnotetext{
${ }^{1}$ Source: MIS items Database.
} 
Table A-2. Chemistry data for MIS items included in regression analysis ${ }^{2}$

\begin{tabular}{|c|c|c|c|c|c|c|c|}
\hline MIS Item Name & Aluminum (ppm) & Beryllium (ppm) & Chlorine (ppm) & Fluorine (ppm) & Magnesium (ppm) & Potassium (ppm) & Sodium (ppm) \\
\hline 053038 & $7.80 \mathrm{E}+03$ & $3.40 \mathrm{E}+02$ & $4.45 \mathrm{E}+04$ & $5.70 \mathrm{E}+03$ & $8.30 \mathrm{E}+03$ & $1.40 \mathrm{E}+04$ & 1.10E+04 \\
\hline 669194 & $7.45 E+02$ & $2.42 \mathrm{E}+03$ & $4.76 \mathrm{E}+02$ & $4.33 \mathrm{E}+01$ & $2.60 \mathrm{E}+02$ & $6.95 E+02$ & $9.81 E+02$ \\
\hline 5501407 & $6.50 \mathrm{E}+01$ & $4.65 E+02$ & $1.29 \mathrm{E}+03$ & $2.20 \mathrm{E}+02$ & $2.90 \mathrm{E}+01$ & $3.32 \mathrm{E}+02$ & $7.50 \mathrm{E}+01$ \\
\hline 5501579 & $1.78 \mathrm{E}+02$ & 8.00E-01 & $7.45 E+02$ & & $8.70 E+01$ & $3.03 E+02$ & $3.00 \mathrm{E}+01$ \\
\hline 07161856 & $1.20 \mathrm{E}+02$ & & $2.40 \mathrm{E}+02$ & $1.00 \mathrm{E}+03$ & $1.32 \mathrm{E}+02$ & $4.01 E+02$ & $4.45 E+02$ \\
\hline $07032282 A$ & $1.81 \mathrm{E}+03$ & $1.00 \mathrm{E}+01$ & $6.03 E+03$ & $1.19 \mathrm{E}+04$ & $1.69 \mathrm{E}+03$ & $1.19 \mathrm{E}+03$ & $2.48 E+03$ \\
\hline $07242165 \mathrm{~A}$ & $3.49 E+03$ & $1.63 E+00$ & $1.13 E+02$ & $9.00 \mathrm{E}+02$ & $4.33 E+01$ & $1.29 E+03$ & $1.20 \mathrm{E}+03$ \\
\hline $07242201 \mathrm{~A}$ & $1.21 E+04$ & $4.25 E+00$ & $4.52 \mathrm{E}+03$ & $1.31 \mathrm{E}+04$ & $1.71 E+03$ & $7.03 \mathrm{E}+03$ & $2.86 \mathrm{E}+03$ \\
\hline ARF-102-85-114-1 & $2.73 E+02$ & $1.42 \mathrm{E}+03$ & $1.40 \mathrm{E}+03$ & $1.30 \mathrm{E}+02$ & $2.59 E+02$ & $4.04 \mathrm{E}+02$ & $8.81 E+02$ \\
\hline ARF-102-85-223 & $1.30 \mathrm{E}+02$ & $4.00 \mathrm{E}+00$ & $5.50 \mathrm{E}+04$ & $6.10 \mathrm{E}+02$ & $5.41 \mathrm{E}+03$ & $1.87 \mathrm{E}+04$ & $1.47 E+04$ \\
\hline ARF-102-85-295 & $5.48 \mathrm{E}+03$ & $1.60 \mathrm{E}+00$ & $7.70 \mathrm{E}+04$ & & $4.04 \mathrm{E}+04$ & $2.33 E+04$ & $2.36 E+04$ \\
\hline ARF-102-85-355 & $3.55 \mathrm{E}+02$ & $4.00 \mathrm{E}+00$ & $7.40 \mathrm{E}+03$ & $3.60 \mathrm{E}+03$ & $1.72 \mathrm{E}+02$ & $1.31 \mathrm{E}+02$ & $3.10 \mathrm{E}+02$ \\
\hline ARF-102-85-365 & $1.67 \mathrm{E}+02$ & $2.60 \mathrm{E}+00$ & $3.81 E+04$ & $1.08 \mathrm{E}+03$ & $5.56 \mathrm{E}+03$ & $2.17 E+04$ & $1.63 E+04$ \\
\hline BLO-39-11-14-004 & $2.00 \mathrm{E}+01$ & $3.30 \mathrm{E}+00$ & $1.50 \mathrm{E}+03$ & & $8.38 E+02$ & $4.88 \mathrm{E}+02$ & $3.00 \mathrm{E}+01$ \\
\hline C00024A & $5.10 \mathrm{E}+02$ & $4.80 \mathrm{E}+03$ & $8.15 \mathrm{E}+03$ & $4.00 \mathrm{E}+02$ & $9.27 \mathrm{E}+03$ & $1.72 \mathrm{E}+04$ & $1.06 \mathrm{E}+04$ \\
\hline C00695 & $4.60 \mathrm{E}+01$ & $4.00 \mathrm{E}+00$ & $6.25 \mathrm{E}+04$ & $3.20 \mathrm{E}+02$ & $8.30 \mathrm{E}+03$ & $2.26 \mathrm{E}+04$ & $2.00 \mathrm{E}+04$ \\
\hline CLLANL025 & $3.27 \mathrm{E}+03$ & $5.00 \mathrm{E}+00$ & $5.72 E+04$ & $1.42 \mathrm{E}+02$ & $3.69 \mathrm{E}+03$ & $2.81 E+04$ & $9.79 \mathrm{E}+03$ \\
\hline MISNE4 & $3.12 \mathrm{E}+03$ & $5.69 \mathrm{E}+00$ & $3.20 \mathrm{E}+04$ & $9.10 \mathrm{E}+02$ & $2.53 E+04$ & $1.12 \mathrm{E}+04$ & $7.26 \mathrm{E}+03$ \\
\hline MT1490 & $5.60 \mathrm{E}+02$ & $6.00 \mathrm{E}+00$ & $4.80 \mathrm{E}+02$ & $1.20 \mathrm{E}+02$ & $1.08 \mathrm{E}+02$ & $5.24 \mathrm{E}+01$ & $3.05 E+02$ \\
\hline PBO-47-09-012-023 & $8.00 \mathrm{E}+01$ & $1.40 \mathrm{E}+00$ & $7.89 \mathrm{E}+02$ & $4.70 \mathrm{E}+01$ & $5.90 \mathrm{E}+01$ & $9.80 \mathrm{E}+01$ & $7.00 \mathrm{E}+01$ \\
\hline PMAXBS & $2.80 \mathrm{E}+02$ & $1.20 \mathrm{E}+01$ & $5.40 \mathrm{E}+04$ & $2.40 \mathrm{E}+02$ & $2.33 E+03$ & $3.57 E+04$ & $1.94 \mathrm{E}+04$ \\
\hline PuF4-1 & & & $1.10 \mathrm{E}+04$ & $1.90 \mathrm{E}+05$ & & & \\
\hline R-437 & & 4.00E-01 & $2.00 \mathrm{E}+01$ & $2.00 \mathrm{E}+01$ & & & $8.25 E+03$ \\
\hline \begin{tabular}{|l} 
R-438 \\
\end{tabular} & $7.51 \mathrm{E}+03$ & $1.30 \mathrm{E}+01$ & $9.00 \mathrm{E}+01$ & $1.20 \mathrm{E}+03$ & $3.06 E+05$ & $1.44 \mathrm{E}+03$ & $8.52 E+03$ \\
\hline SCP711-46 & $9.00 \mathrm{E}+00$ & $4.99 \mathrm{E}+00$ & $2.00 \mathrm{E}+01$ & $4.00 \mathrm{E}+01$ & $1.26 \mathrm{E}+02$ & $3.42 \mathrm{E}+02$ & $4.77 \mathrm{E}+02$ \\
\hline
\end{tabular}

\footnotetext{
${ }^{2}$ Source: MIS items Database.
} 
Appendix B

Residuals and Response vs. Fit Plots 


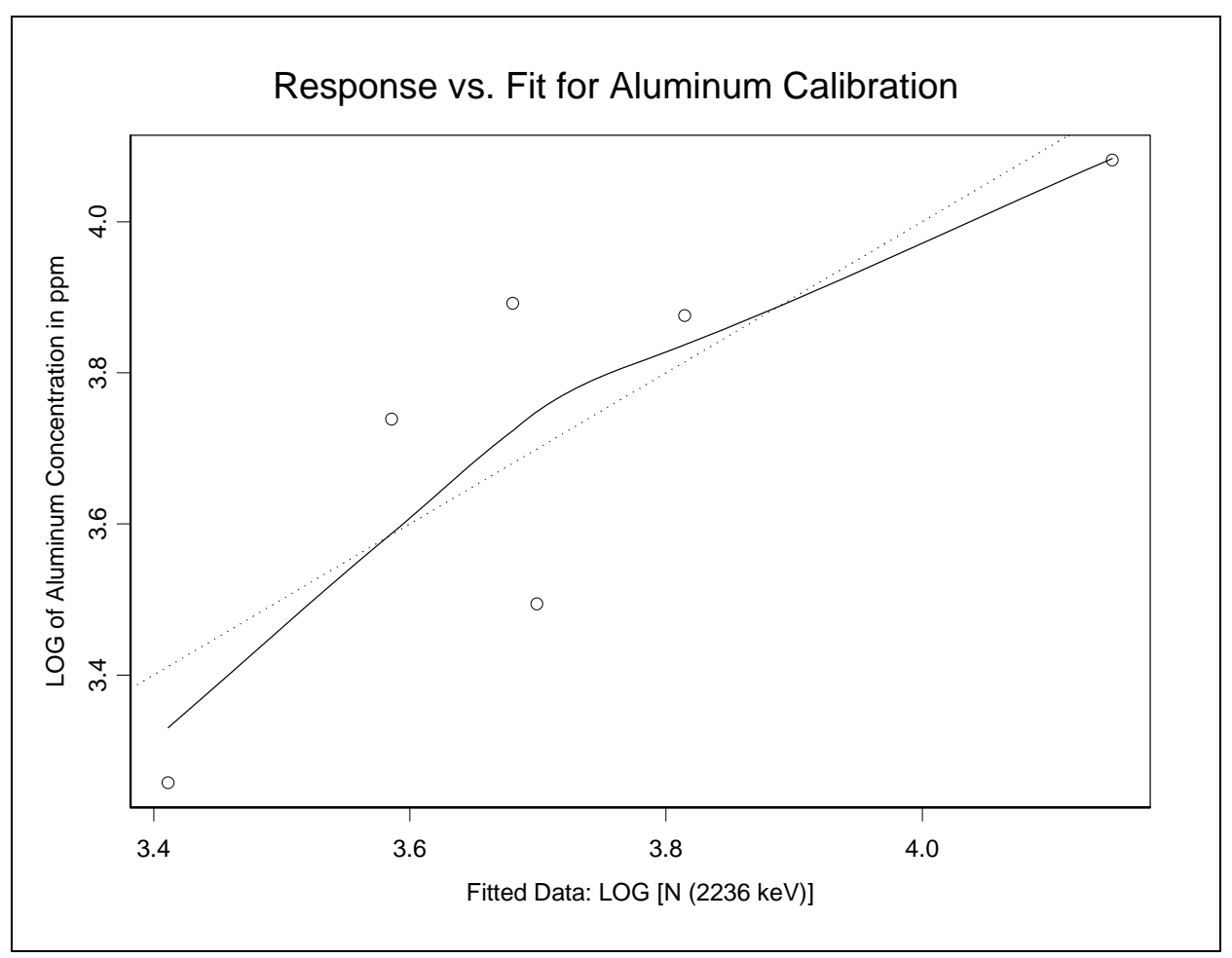

Figure B-1. Actual data vs. fit data for the Al calibration.

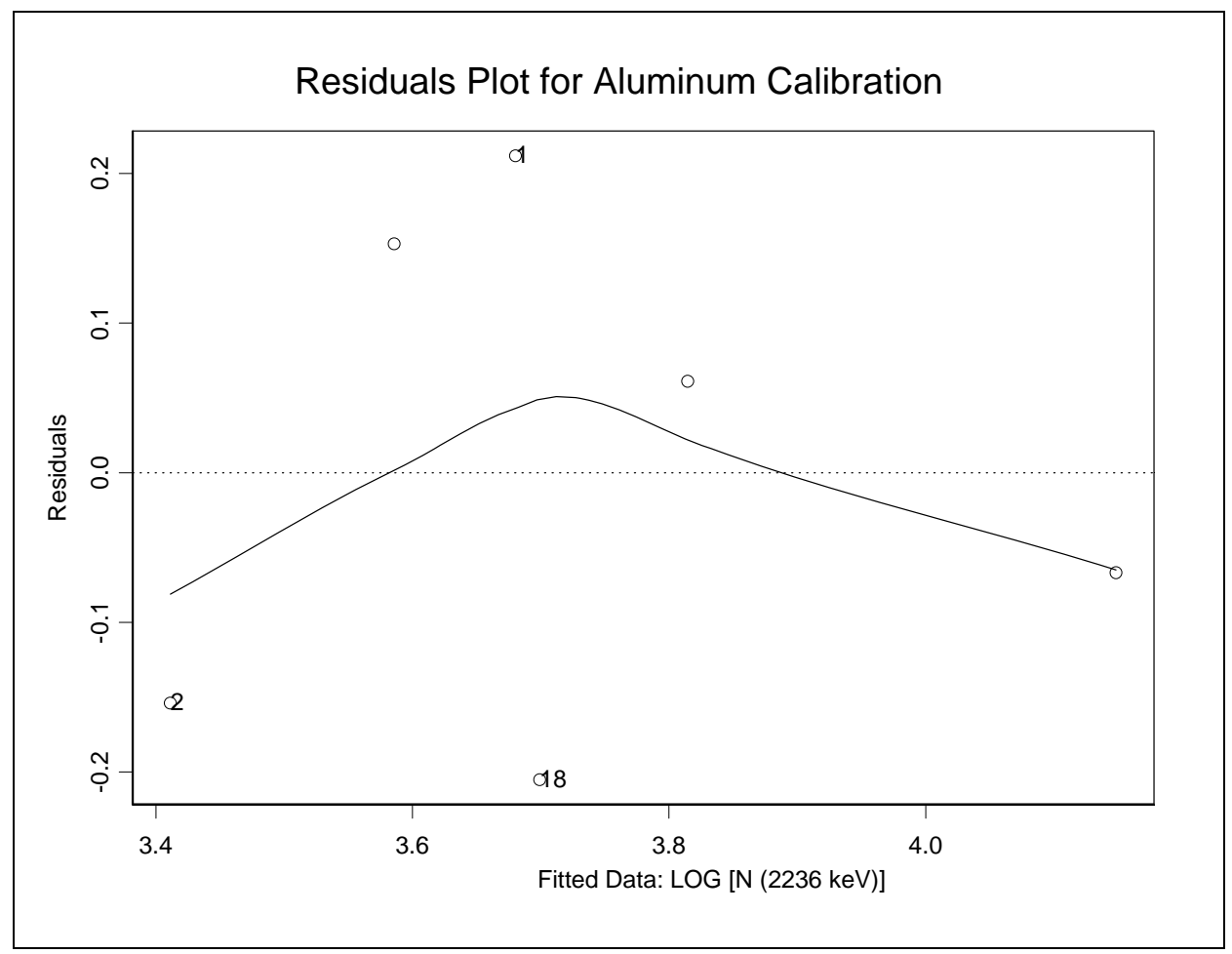

Figure B-2. Residuals plot showing the differences between the actual and predicted values for the Al calibration line. 


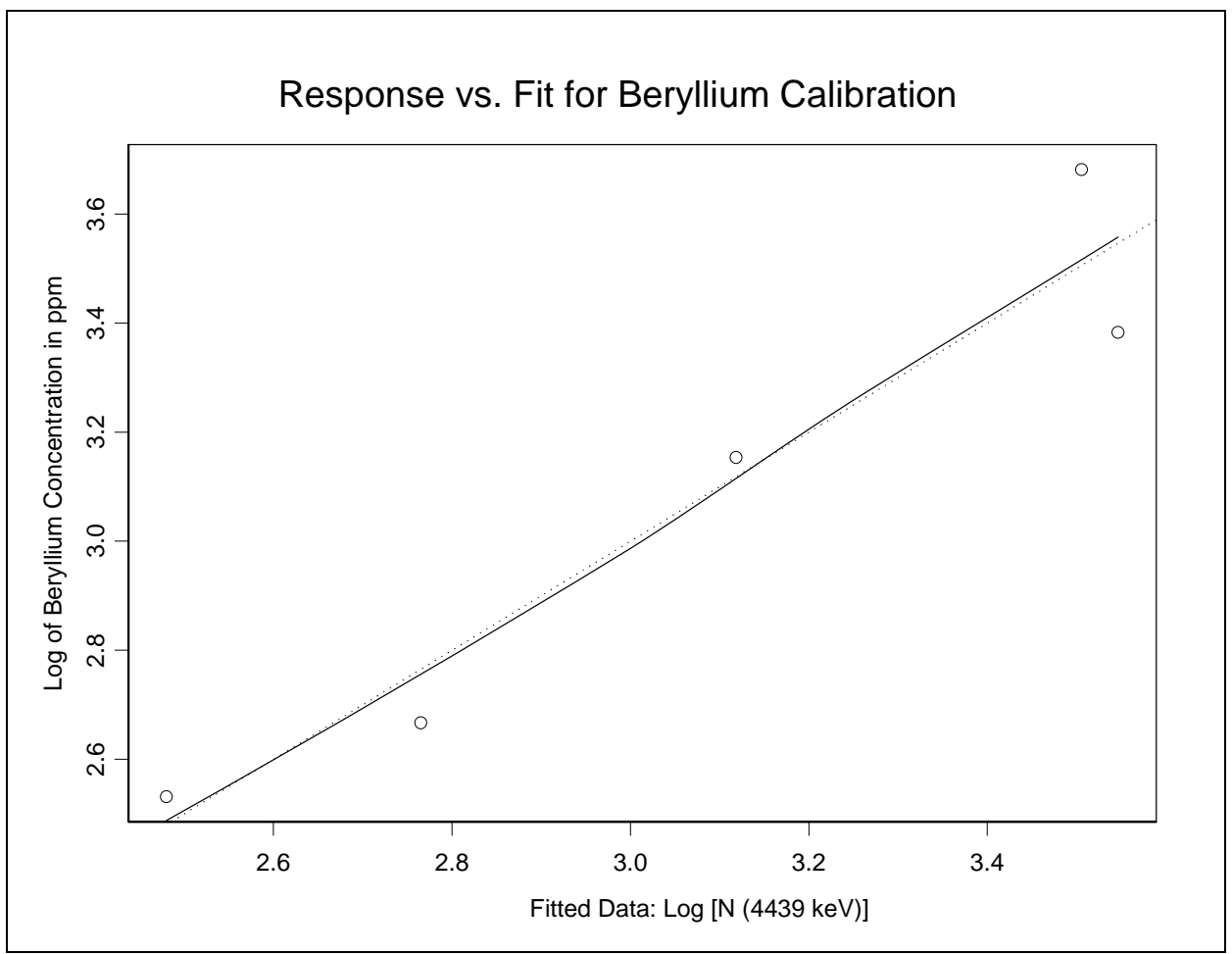

Figure B-3. Actual data vs. fit data for the Be calibration.

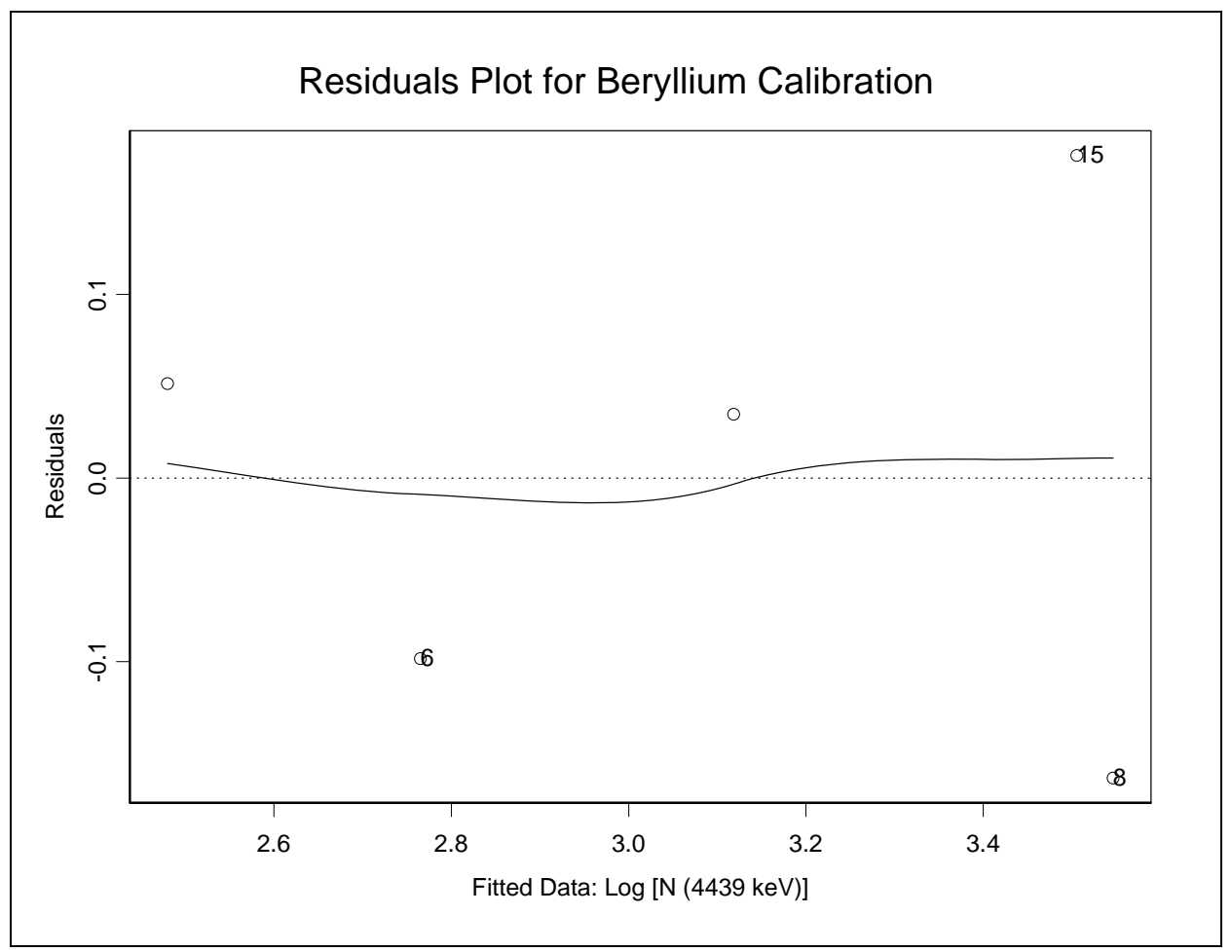

Figure B-4. Residuals plot showing the differences between the actual and predicted values for the Be calibration line. 


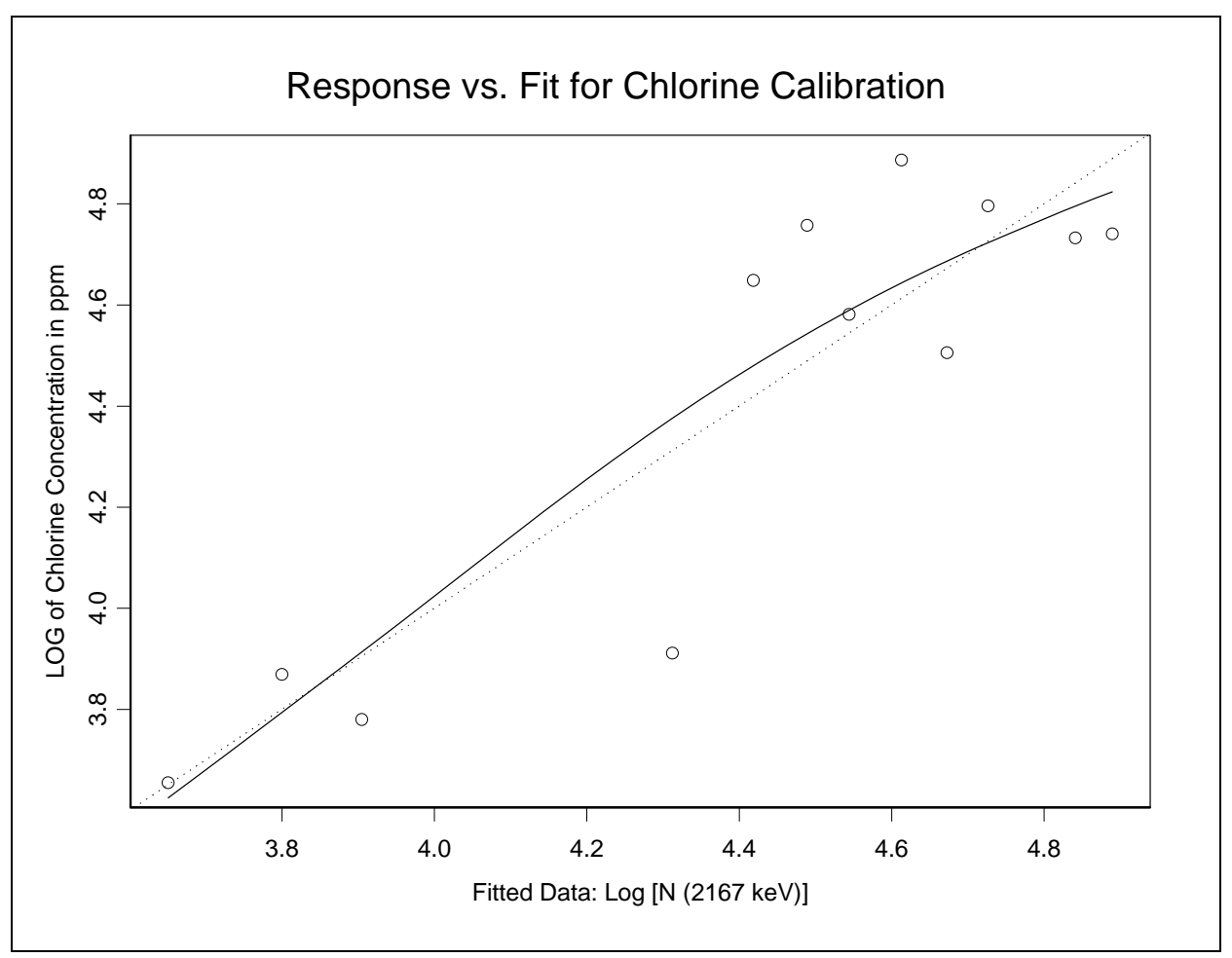

Figure B-5. Actual data vs. fit data for the Cl calibration.

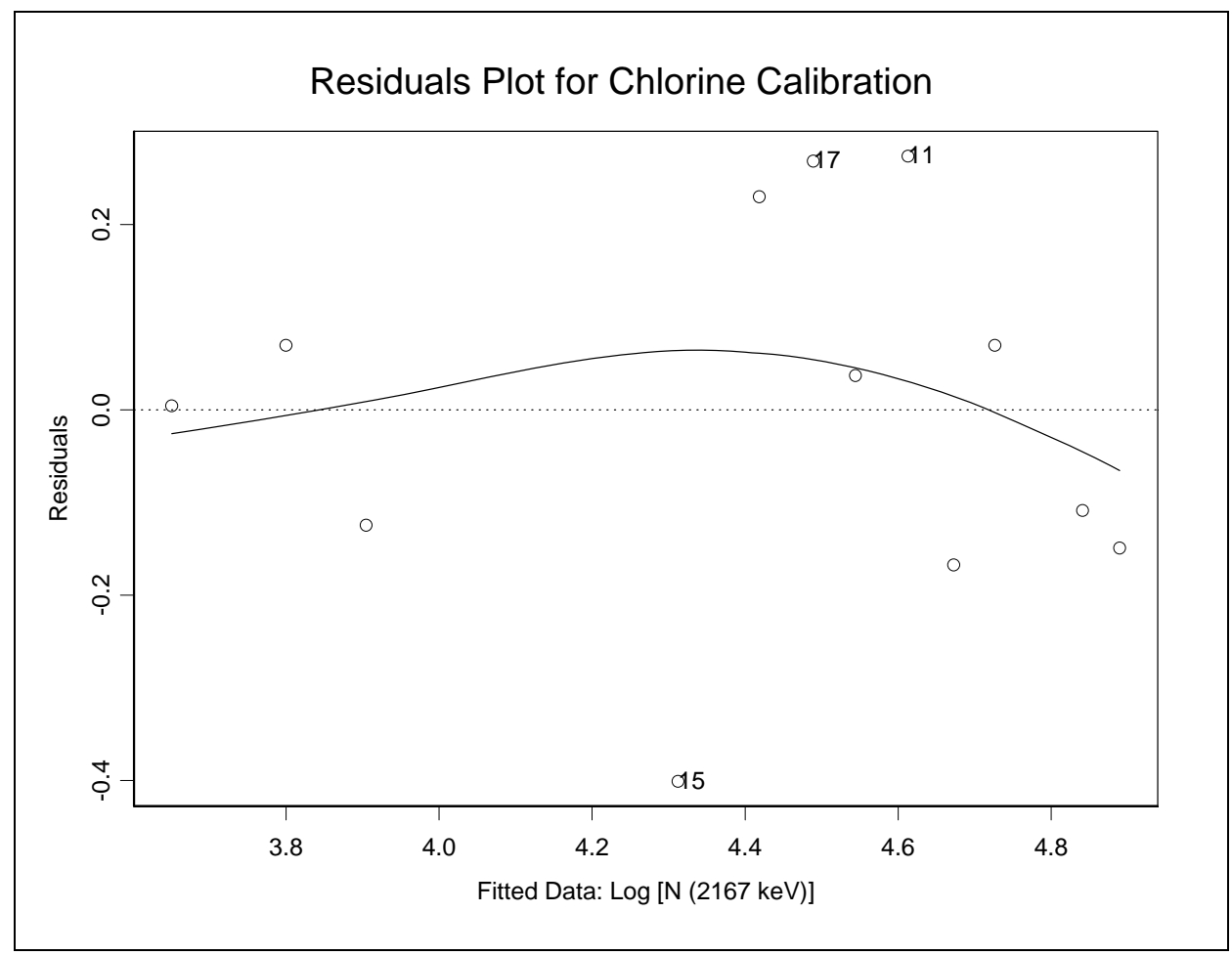

Figure B-6. Residuals plot showing the differences between the actual and predicted values for the $\mathrm{Cl}$ calibration line. 


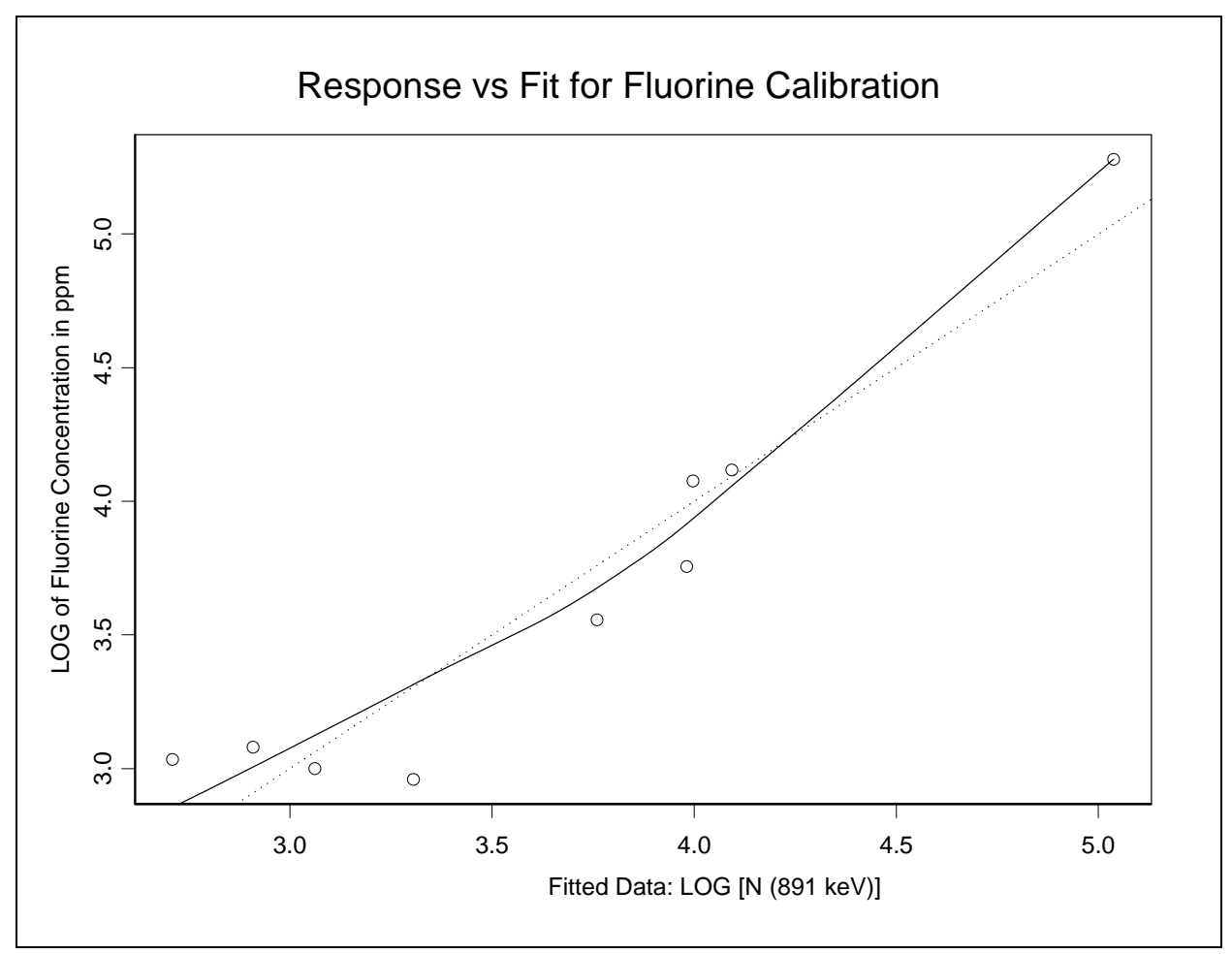

Figure B-7. Actual data vs. fit data for the F calibration.

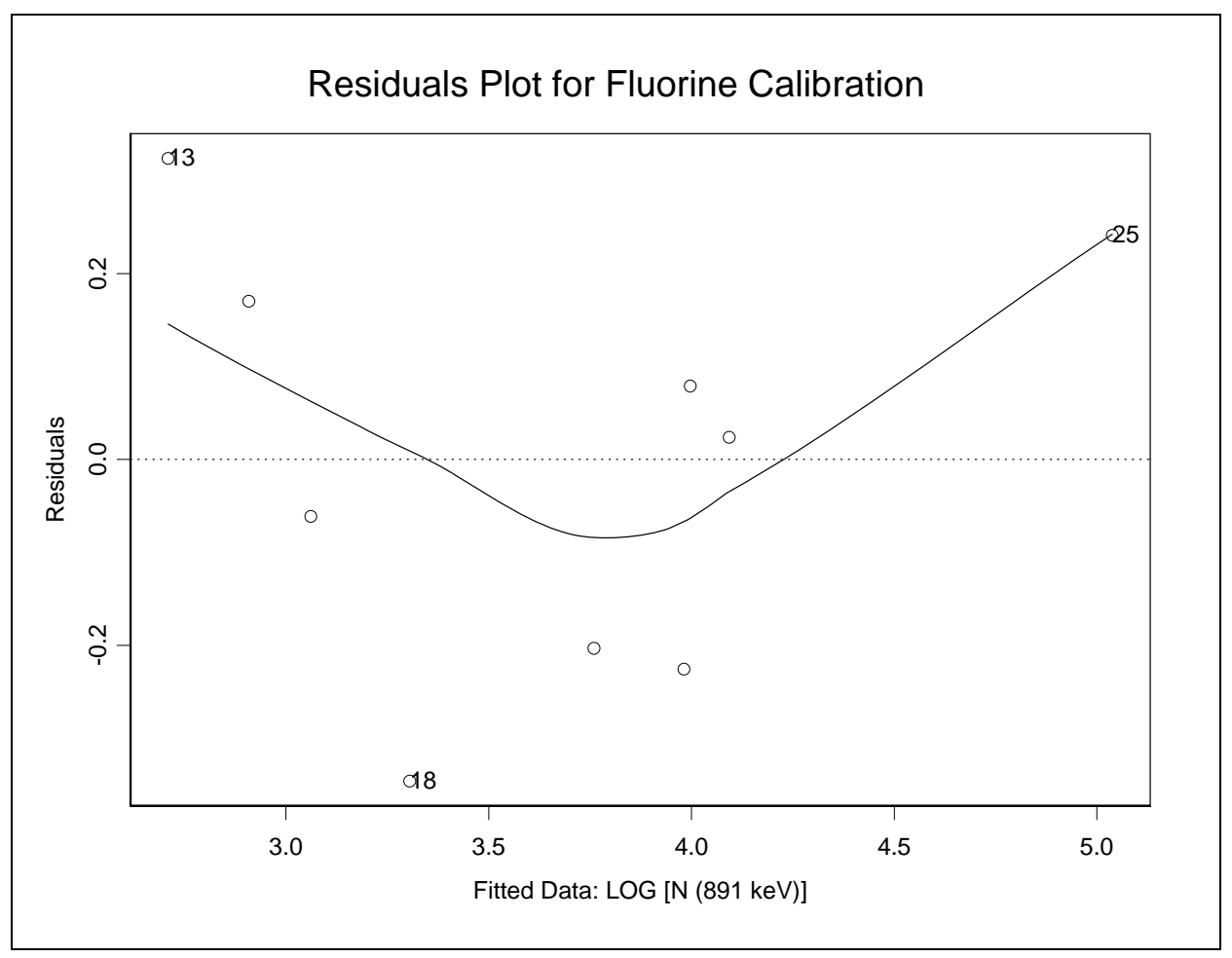

Figure B-8. Residuals plot showing the differences between the actual and predicted values for the $F$ calibration line. 


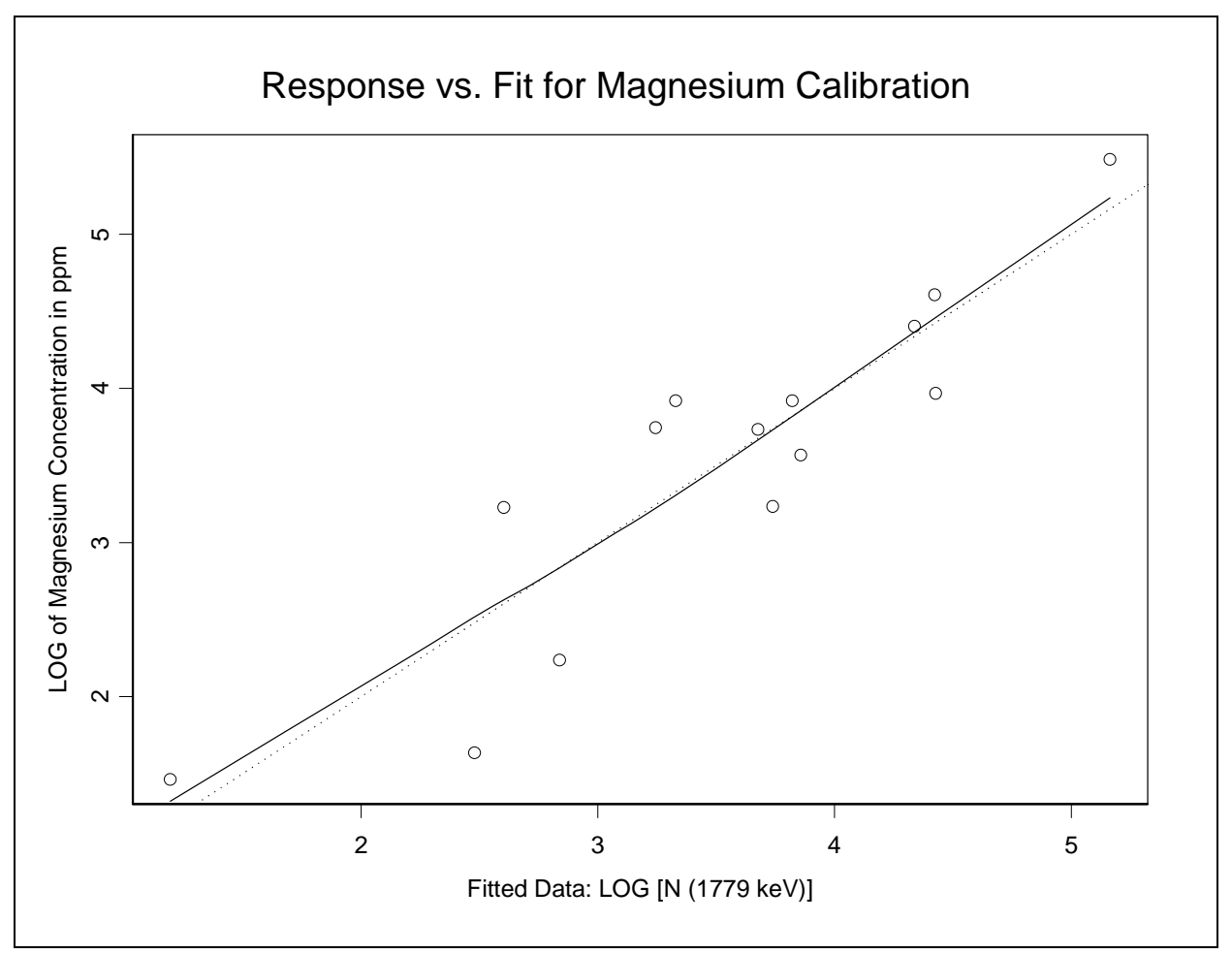

Figure B-9. Actual data vs. fit data for the Mg calibration.

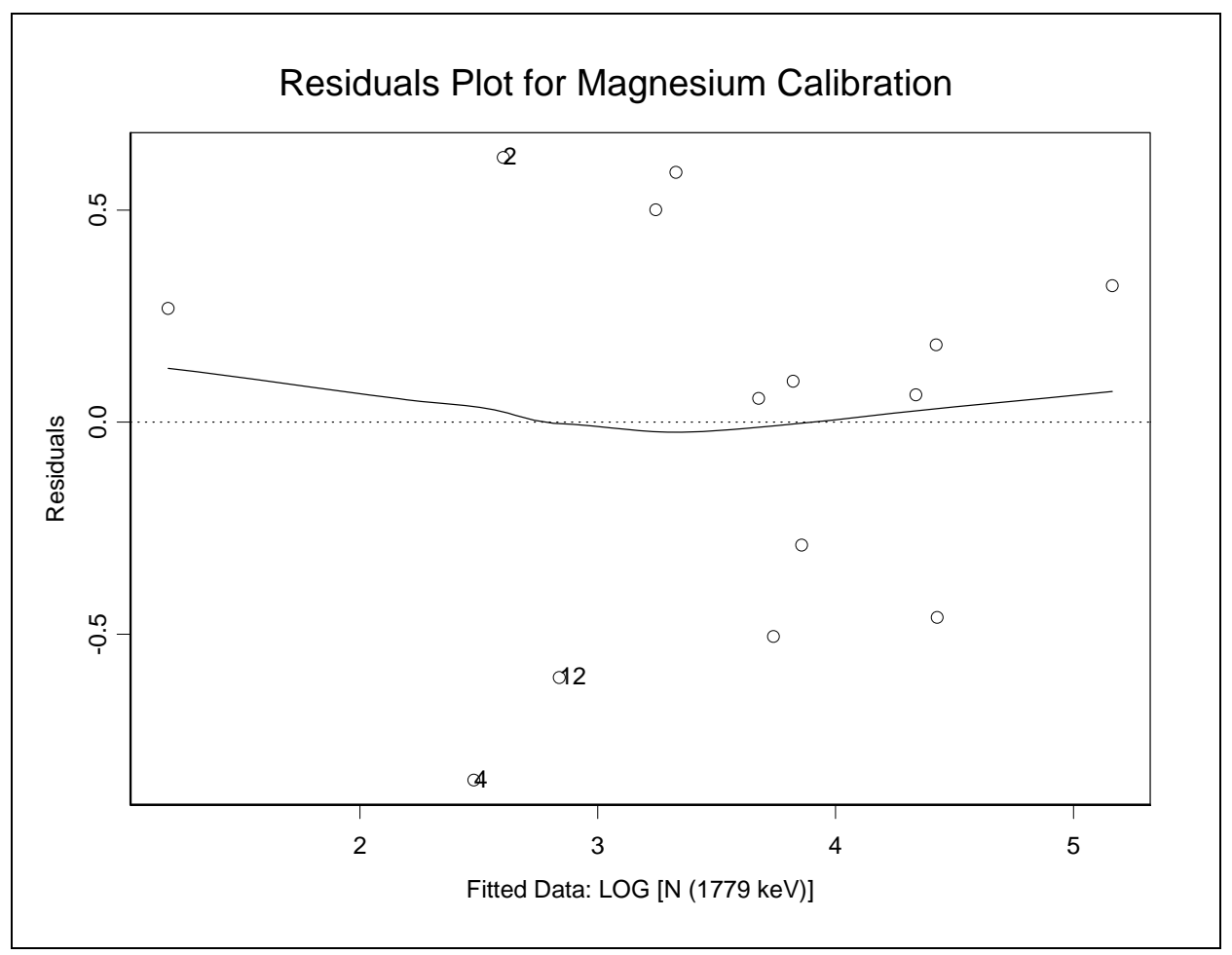

Figure B-10. Residuals plot showing the differences between the actual and predicted values for the Mg calibration line. 


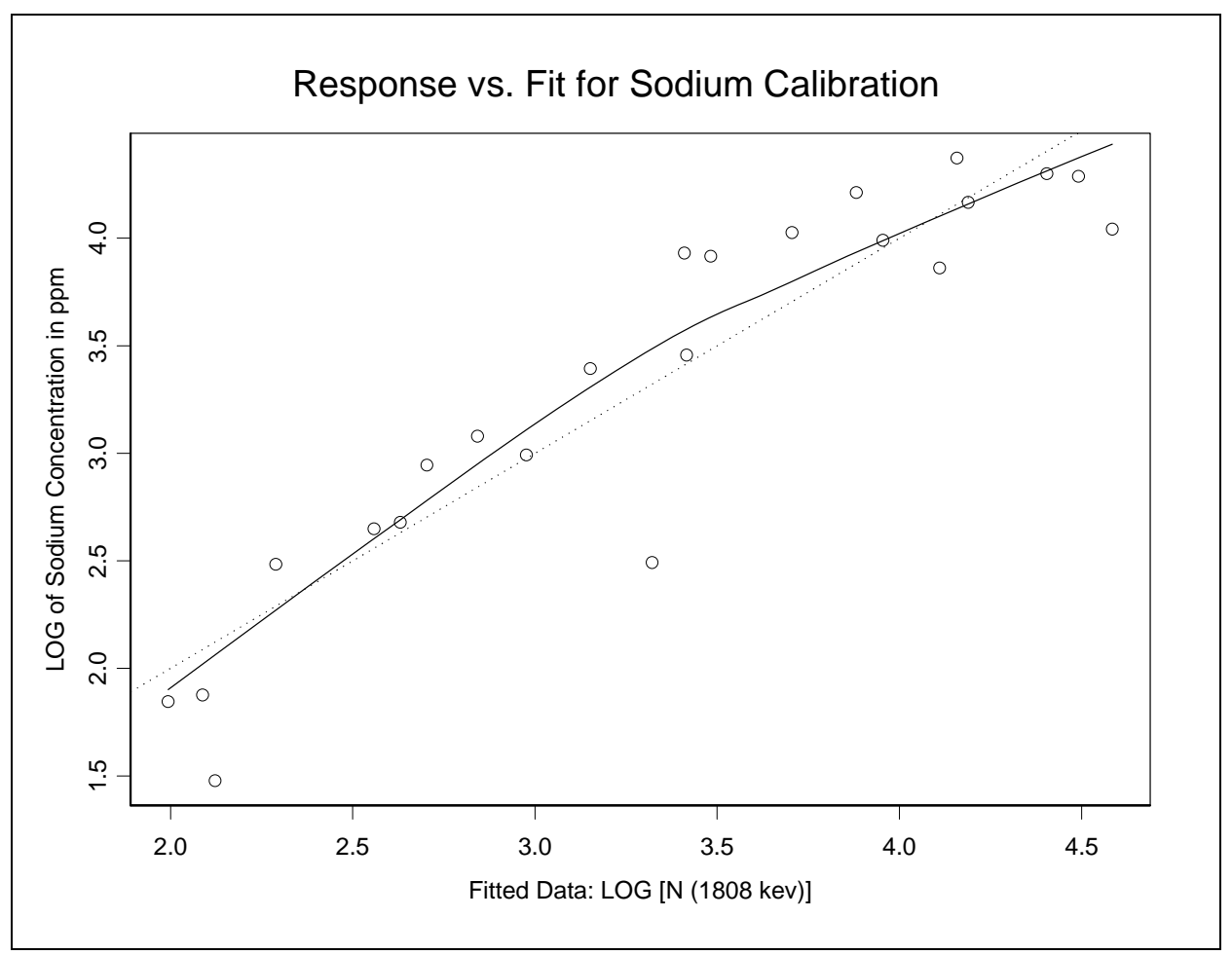

Figure B-11. Actual data vs. fit data for the Na calibration.

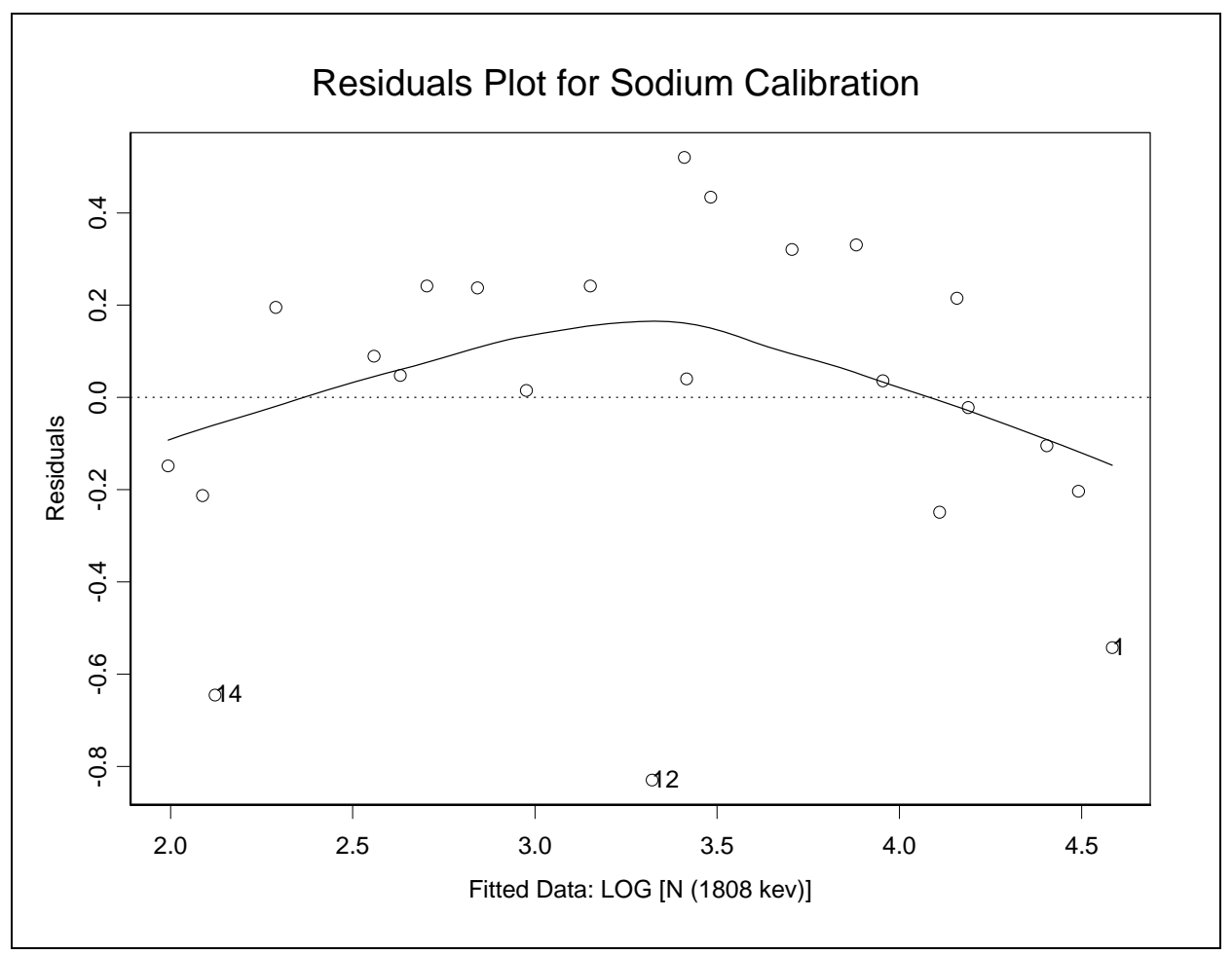

Figure B-12. Residuals plot showing the differences between the actual and predicted values for the Na calibration line. 
Appendix C

Box Plots Comparing the Distributions

of Normalized Count Data Across Sites 


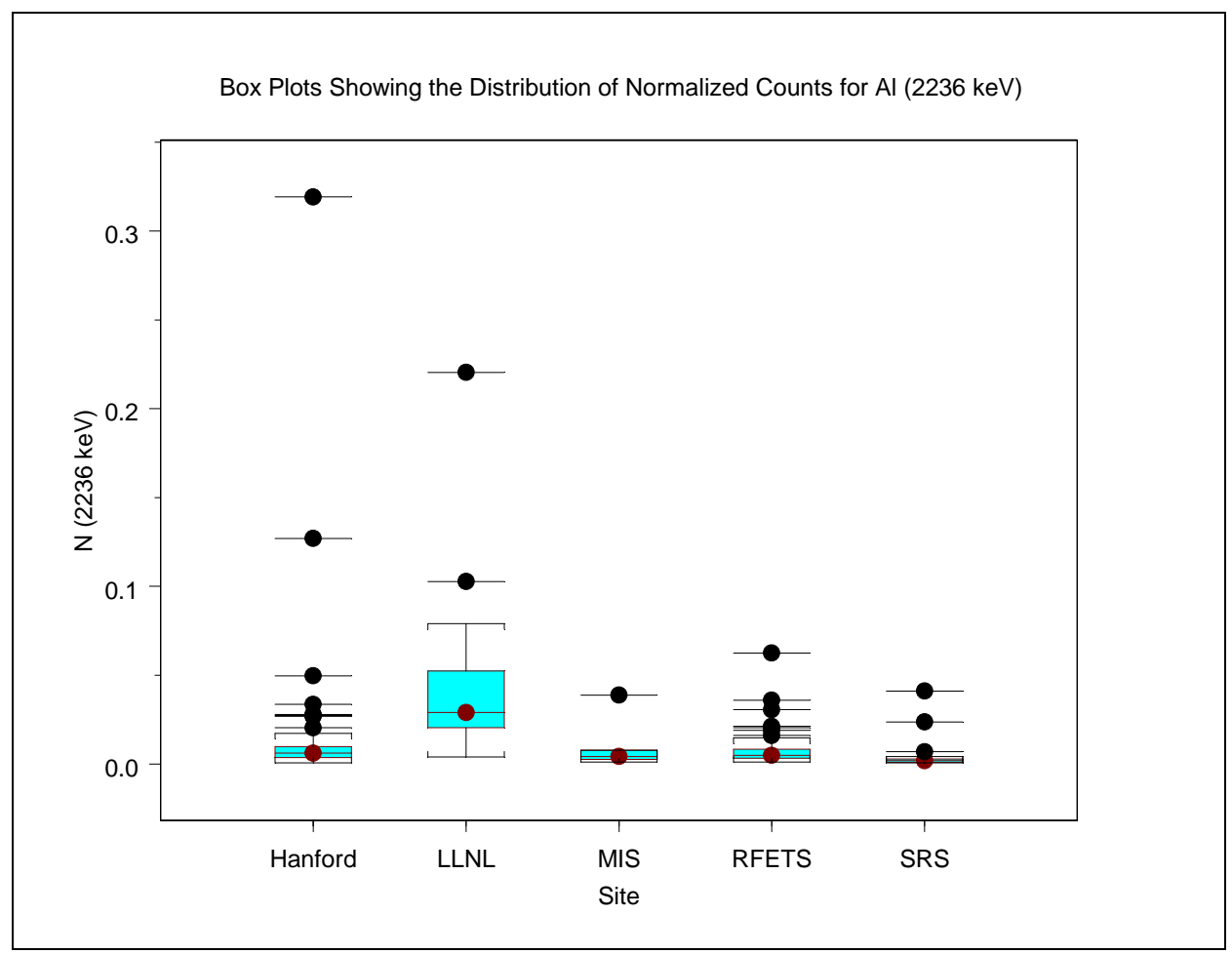

Figure C-1. Box plots comparing the ranges of count data for Al across all sites.

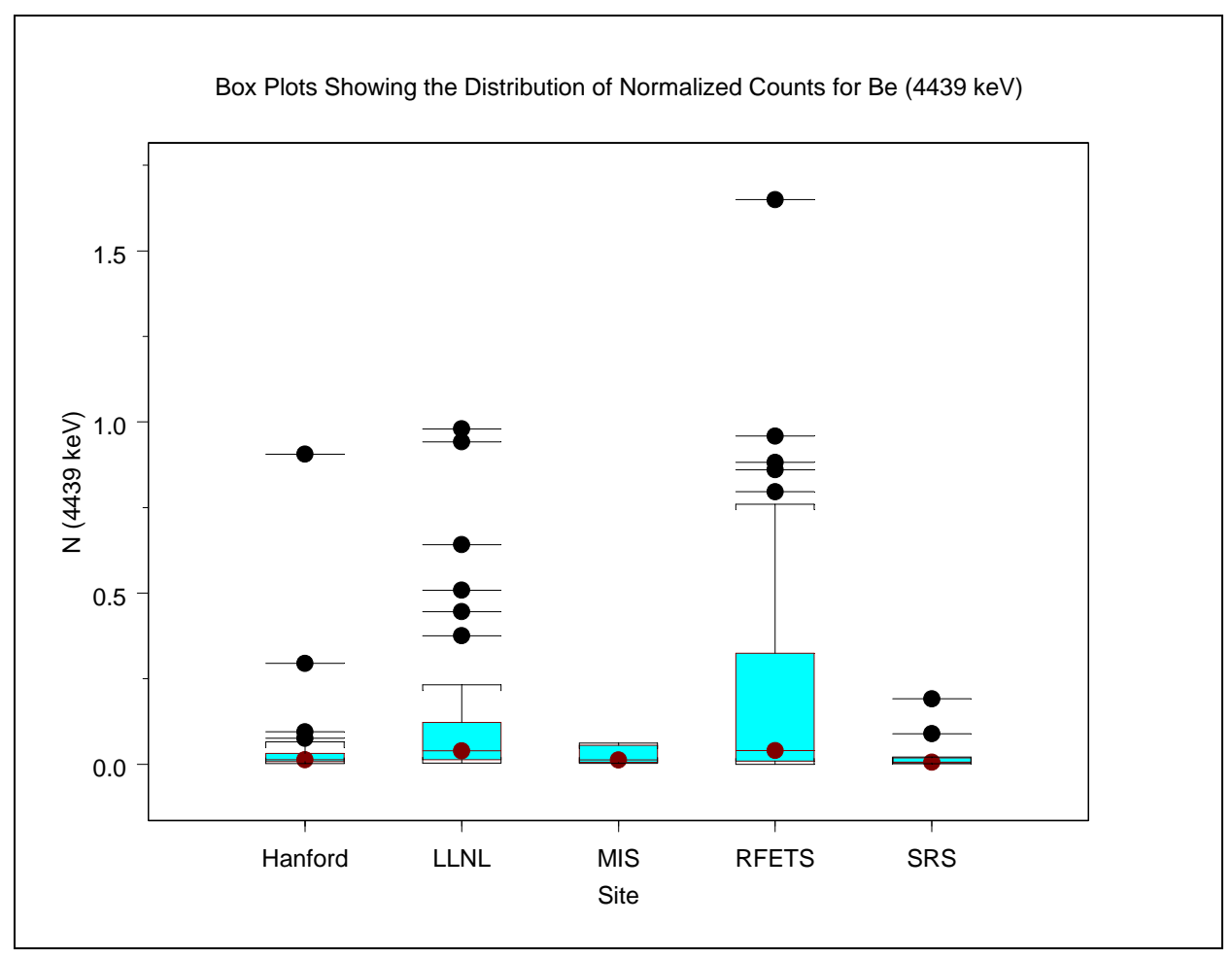

Figure C-2. Box plots comparing the ranges of count data for Be across all sites. 


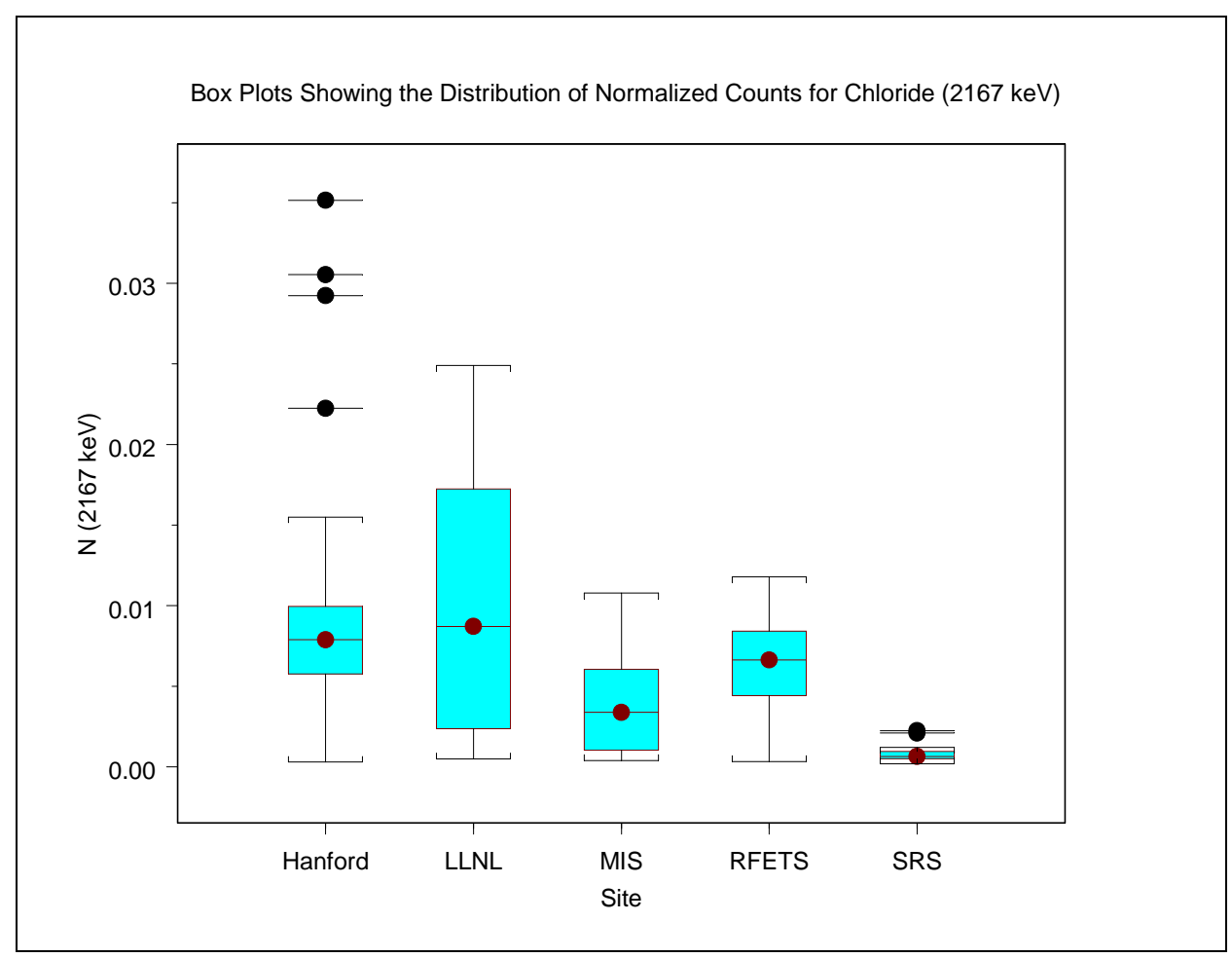

Figure C-3. Box plots comparing the ranges of count data for $\mathrm{Cl}$ across all sites.

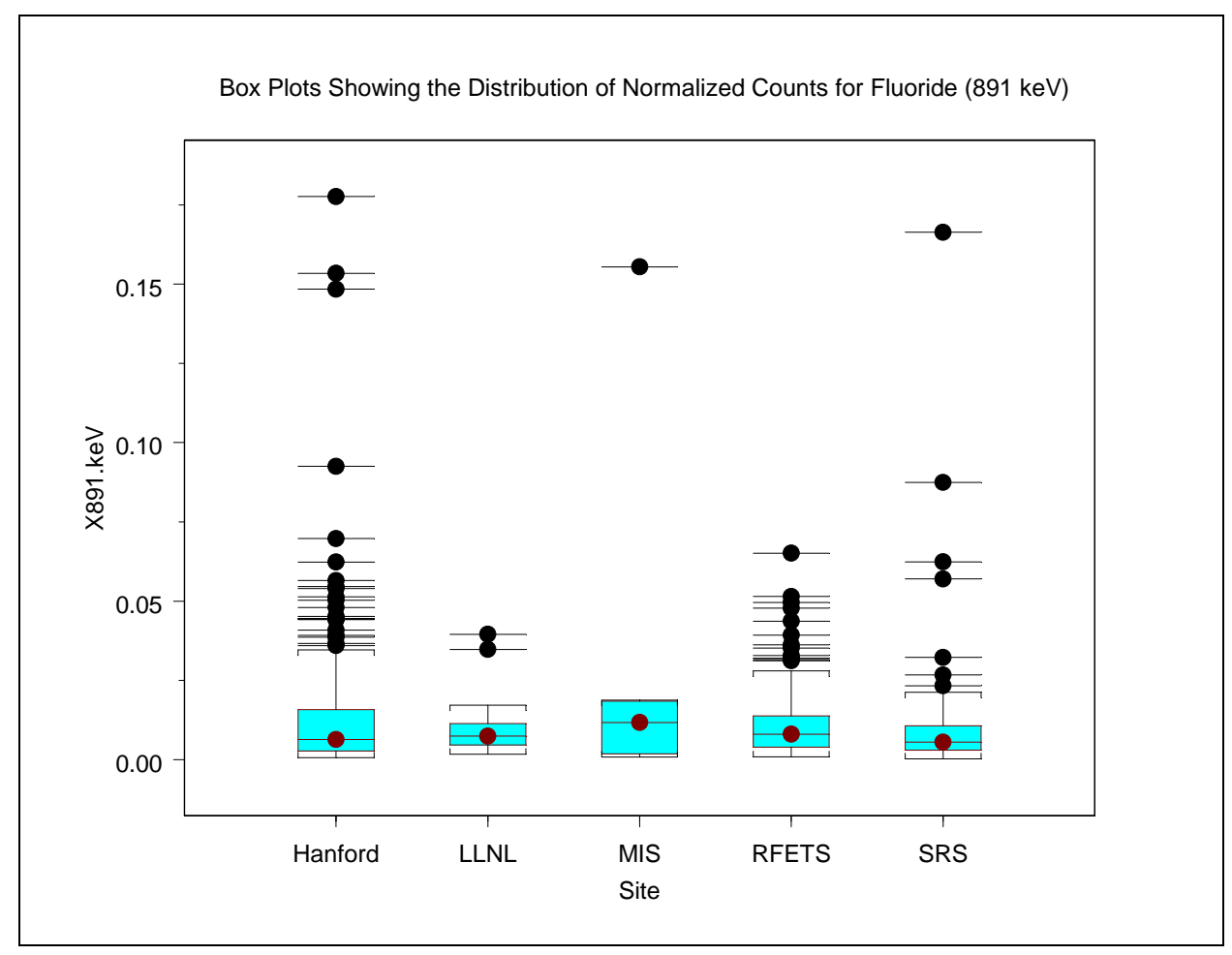

Figure C-4. Box plots comparing the ranges of count data for $F$ across all sites. 
Box Plots Showing the Distribution of Normalized Counts for Magnesium (1779 keV)

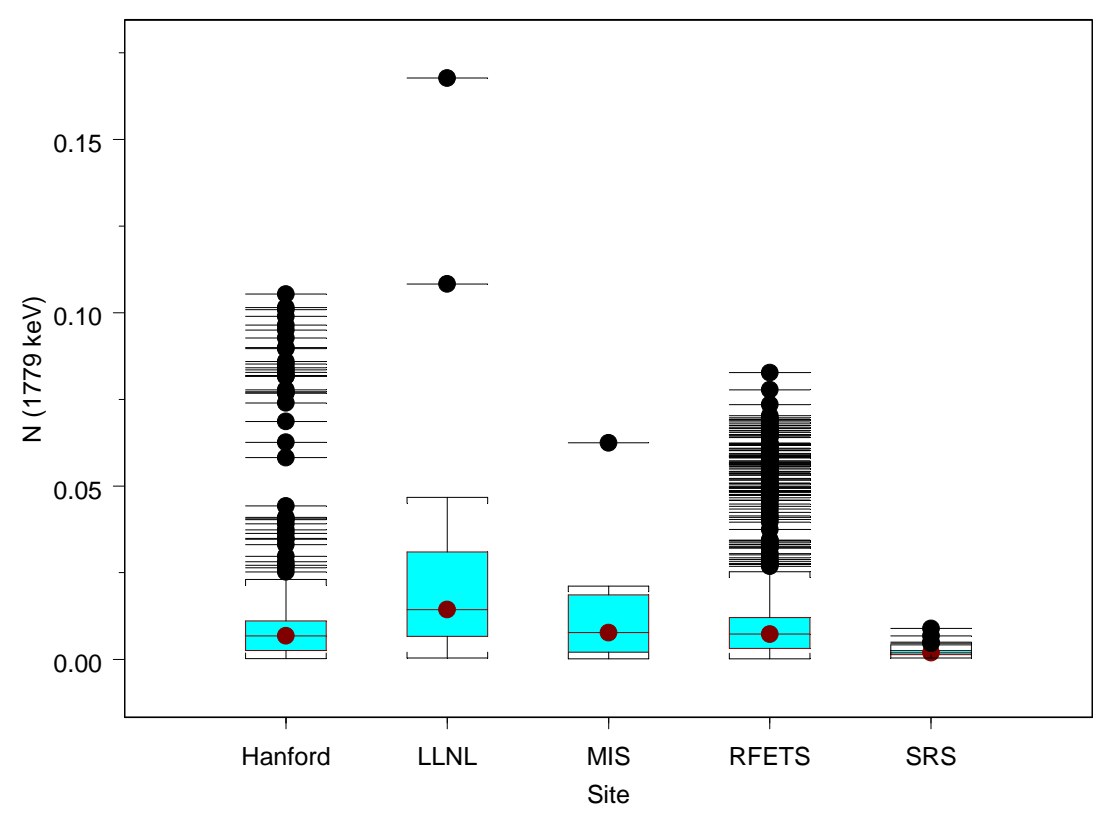

Figure C-5. Box plots comparing the ranges of count data for Mg across all sites.

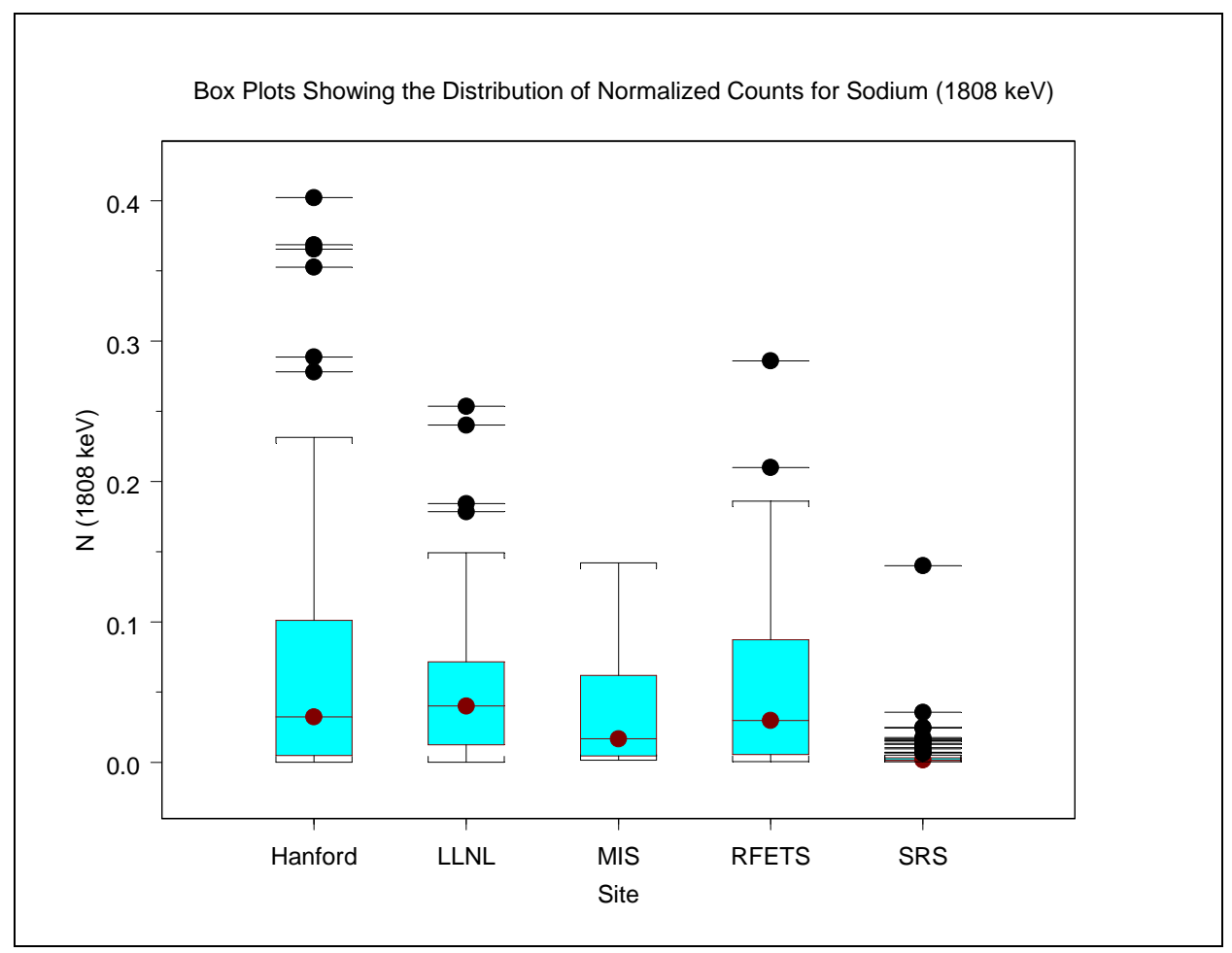

Figure C-6. Box plots comparing the ranges of count data for Na across all sites. 


\section{Appendix D}

Histograms Showing the Predicted Concentrations of Impurities in 3013 Containers 


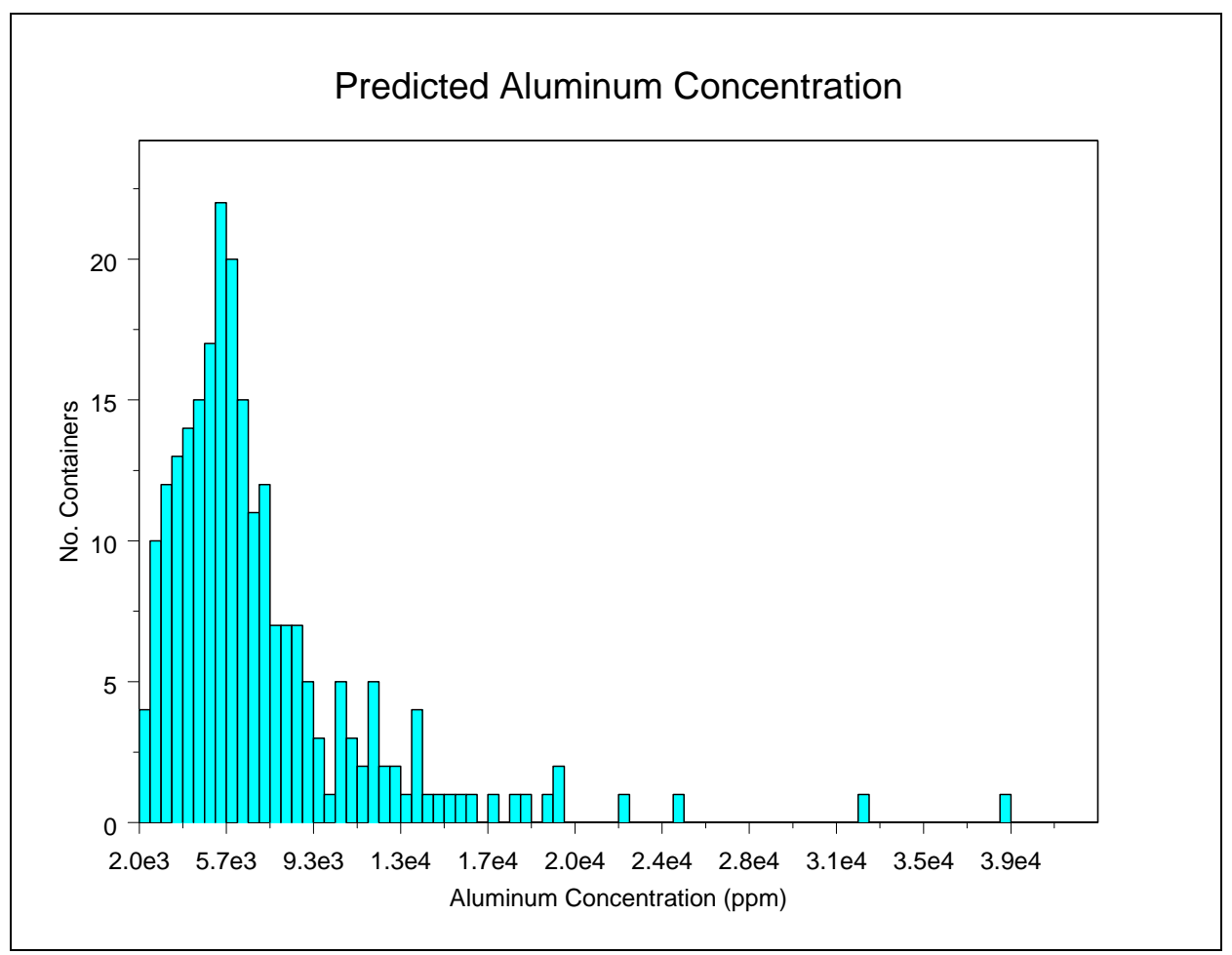

Figure D-1. Distribution of aluminum in 3013 containers.

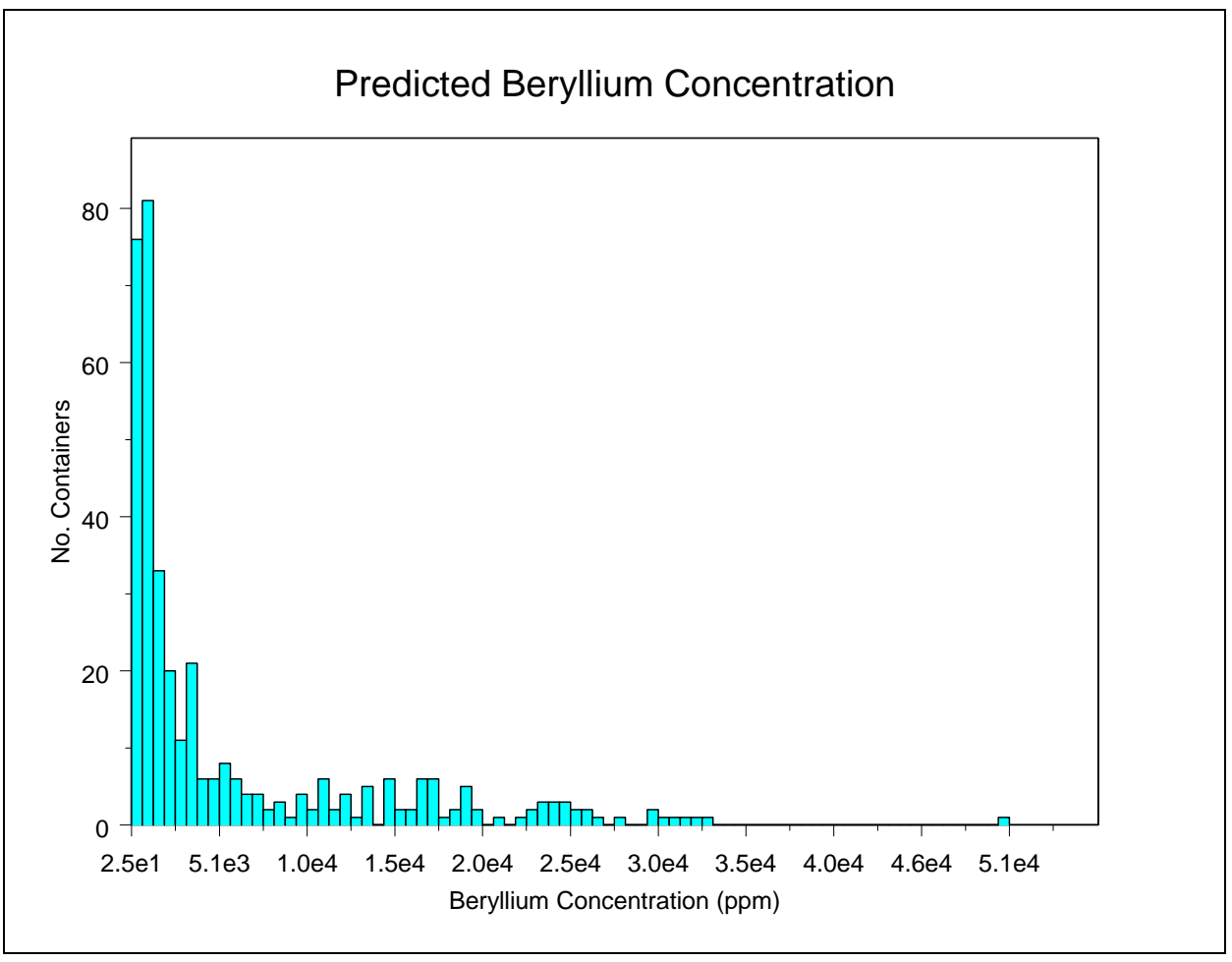

Figure D-2. Distribution of beryllium in 3013 containers. 


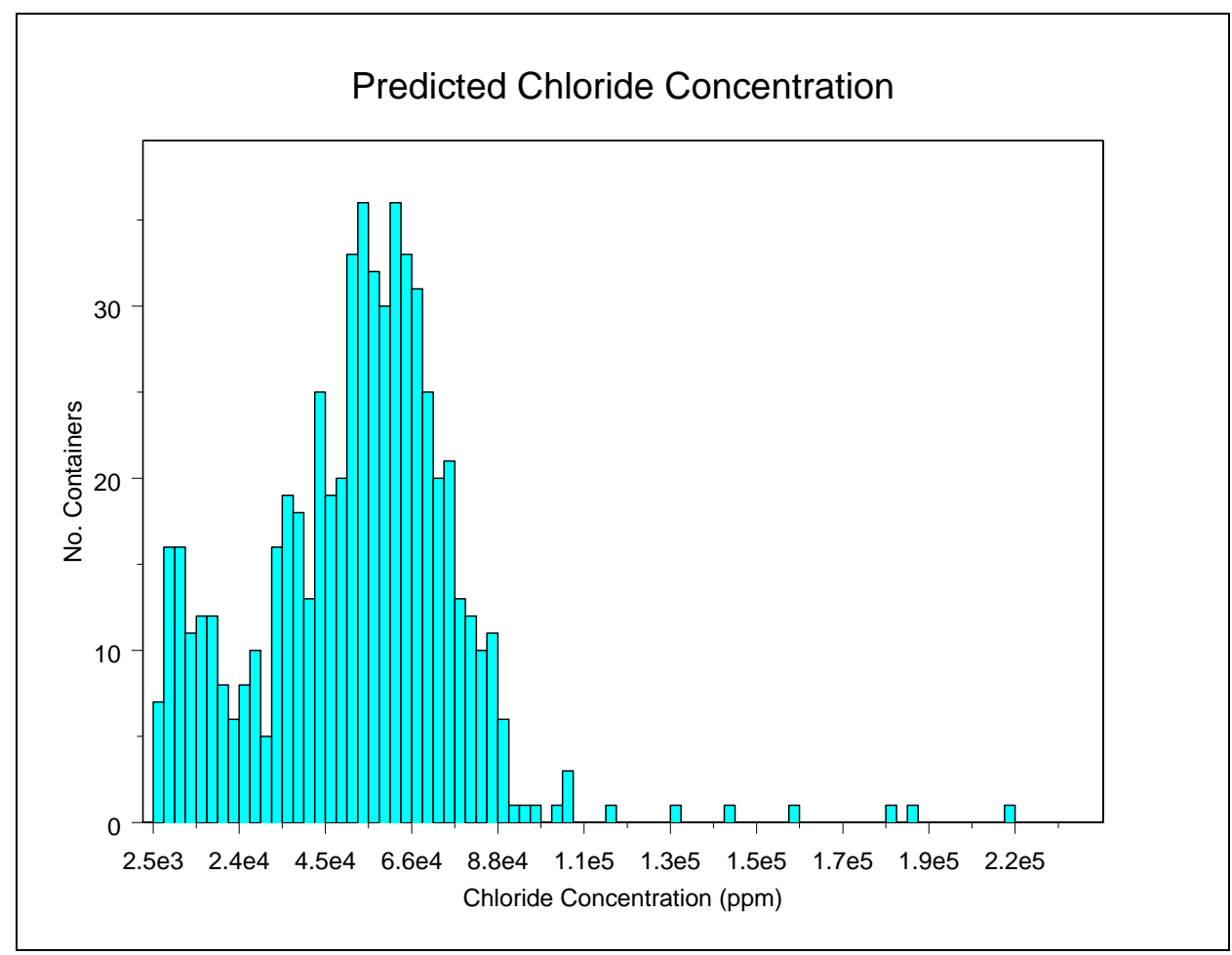

Figure D-3. Distribution of chloride in 3013 containers.

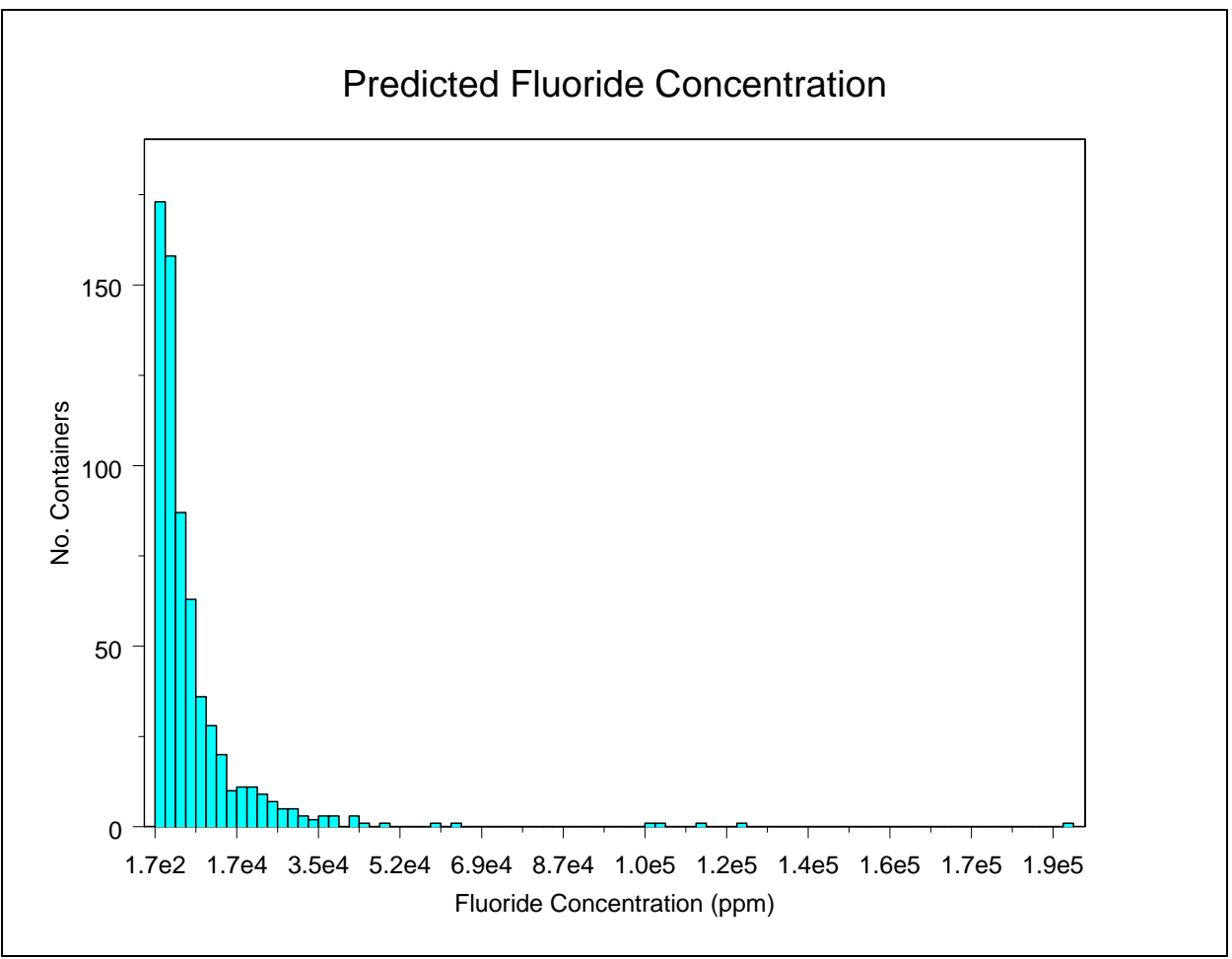

Figure D-4. Distribution of fluoride in 3013 containers. 


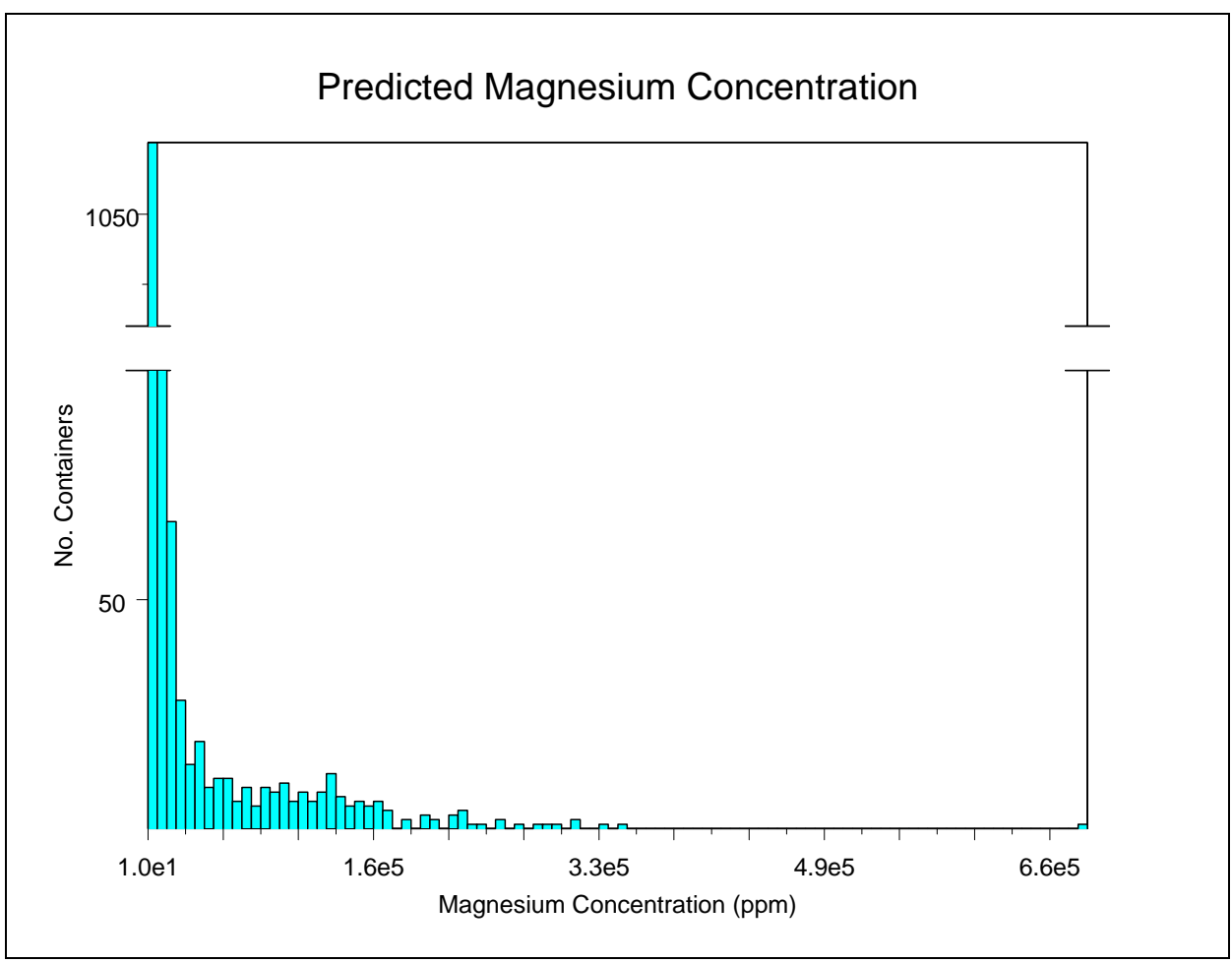

Figure D-5. Distribution of magnesium in 3013 containers.

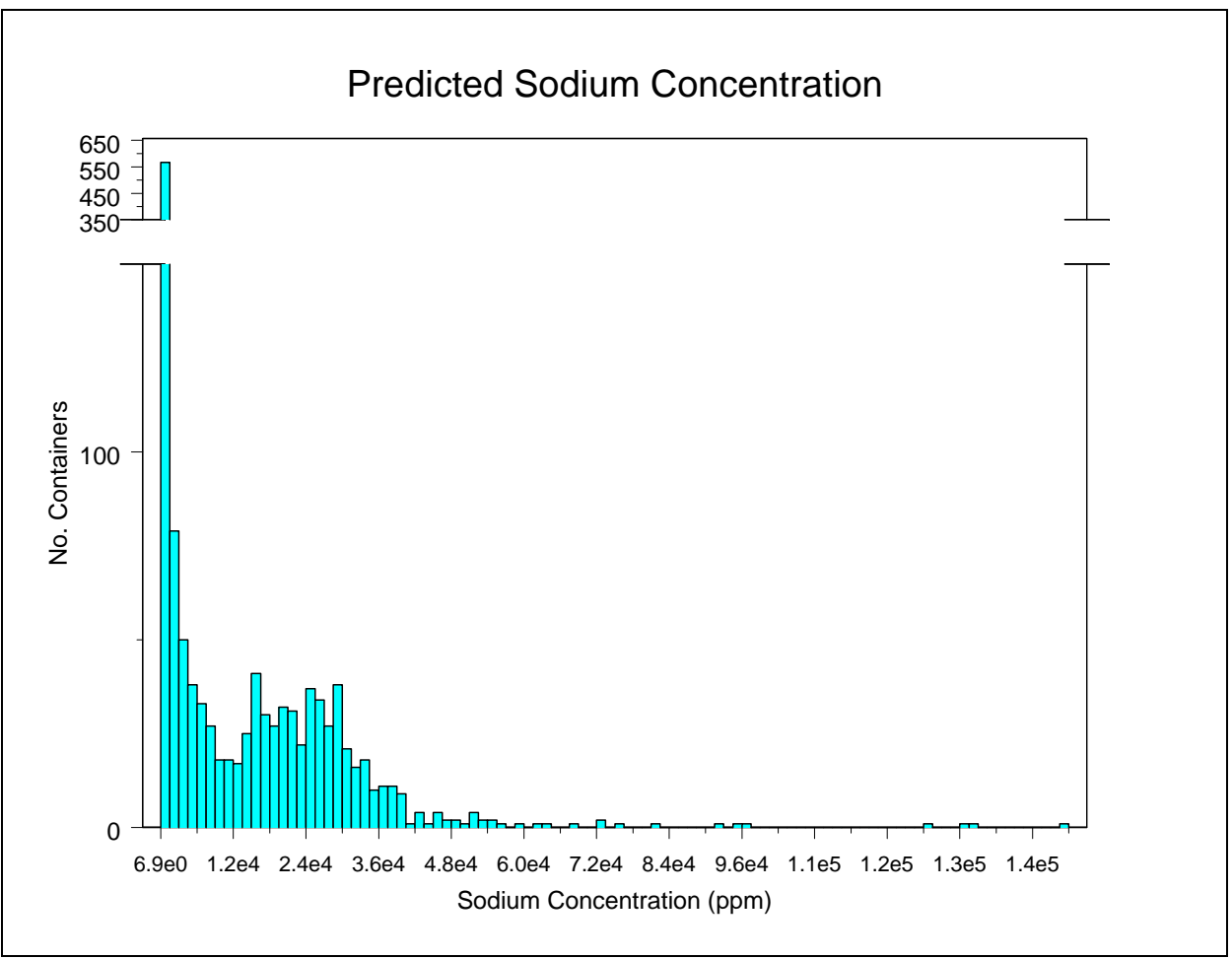

Figure D-6. Distribution of sodium in 3013 containers. 
This report has been reproduced directly from the best available copy. It is available electronically on the Web (http://www.doe.gov/bridge).

Copies are available for sale to U.S. Department of Energy employees and contractors from:

Office of Scientific and Technical Information P.O. Box 62

Oak Ridge, TN 37831

(865) 576-8401

Copies are available for sale to the public from: National Technical Information Service

U.S. Department of Commerce

5285 Port Royal Road

Springfield, VA 22161

(800) 553-6847 


\section{Los Alamos}

NATIONAL LABORATORY

EST.1943 